\title{
Highly Activated Vinyl Hydrogen in a Significantly Twisted Styrene
}

Hajime Mori, ${ }^{\dagger}$, q, $^{*}$ Takafumi Matsuo, ${ }^{\dagger}$ Yasunori Yoshioka, $§$ and Shigeo Katsumura ${ }^{\dagger}, *$

$\dagger$ School of Science and Technology, Kwansei Gakuin University, 2-1 Gakuen, Sanda, Hyogo, 669-1337, Japan $§$ Department of Chemistry, Mie University, 1577 Kurimamachiya-cho, Tsu-shi,, Mie, 514-8507 Japan " Present address: Industrial Technology Center of Wakayama Prefecture, Ogura 60, Wakayama, 649-6261, Japan

\section{Supporting Information}

${ }^{1} \mathrm{H}$ and ${ }^{13} \mathrm{C}$ NMR Spectra for 1-6, 8-12

${ }^{1} \mathrm{H}$ NMR Spectra for the base treatment of $\mathbf{1 b}$ and $\mathbf{4 b}$

${ }^{1} \mathrm{H}$ and ${ }^{13} \mathrm{C}$ NMR Spectra for 23, 24

X-ray crystallographic data

Calculated total energies and Cartesian coordinates pp S2-S29

pp S30-S32

pp S33-S36

pp S37-S41

pp S42-S47 


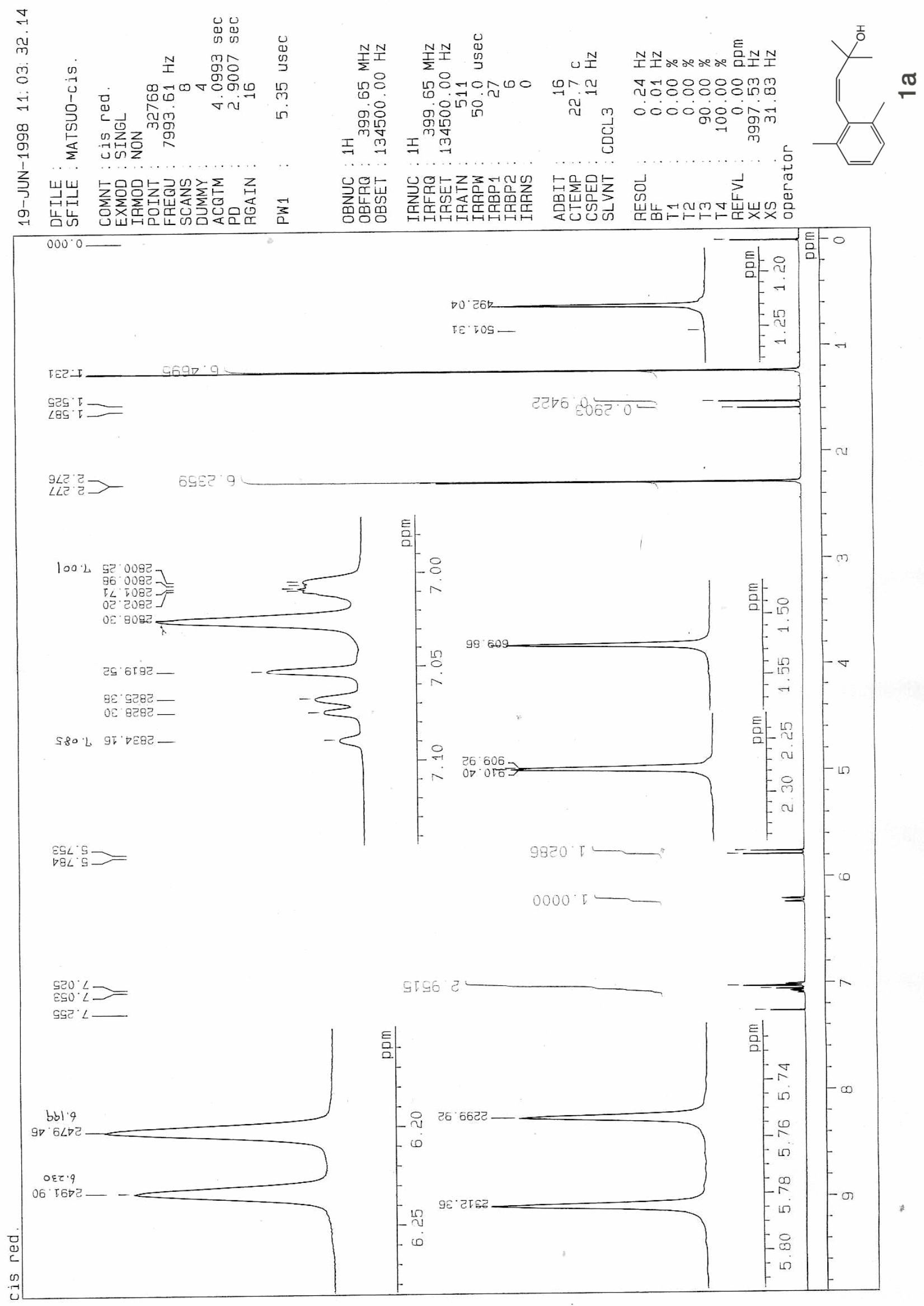



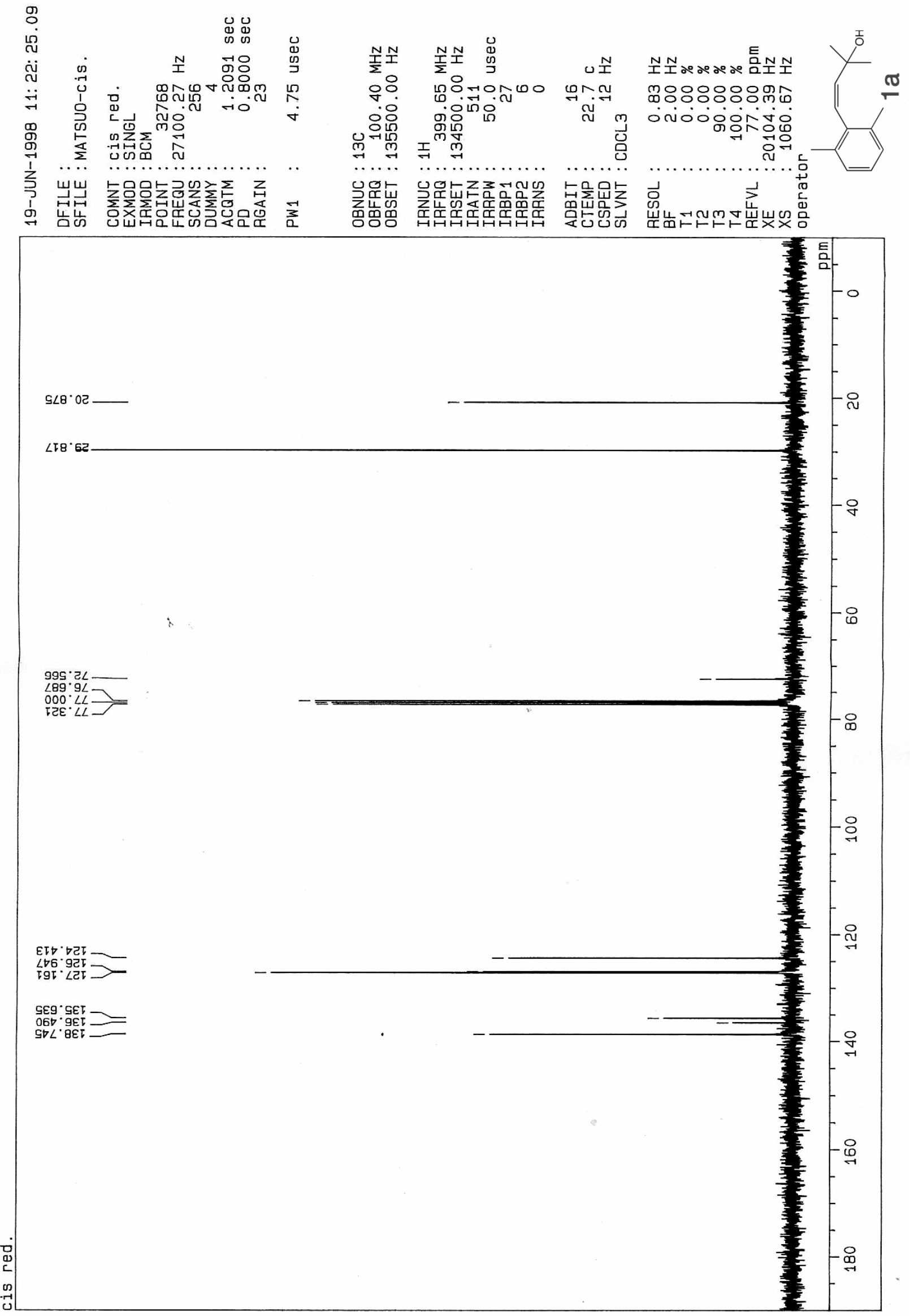

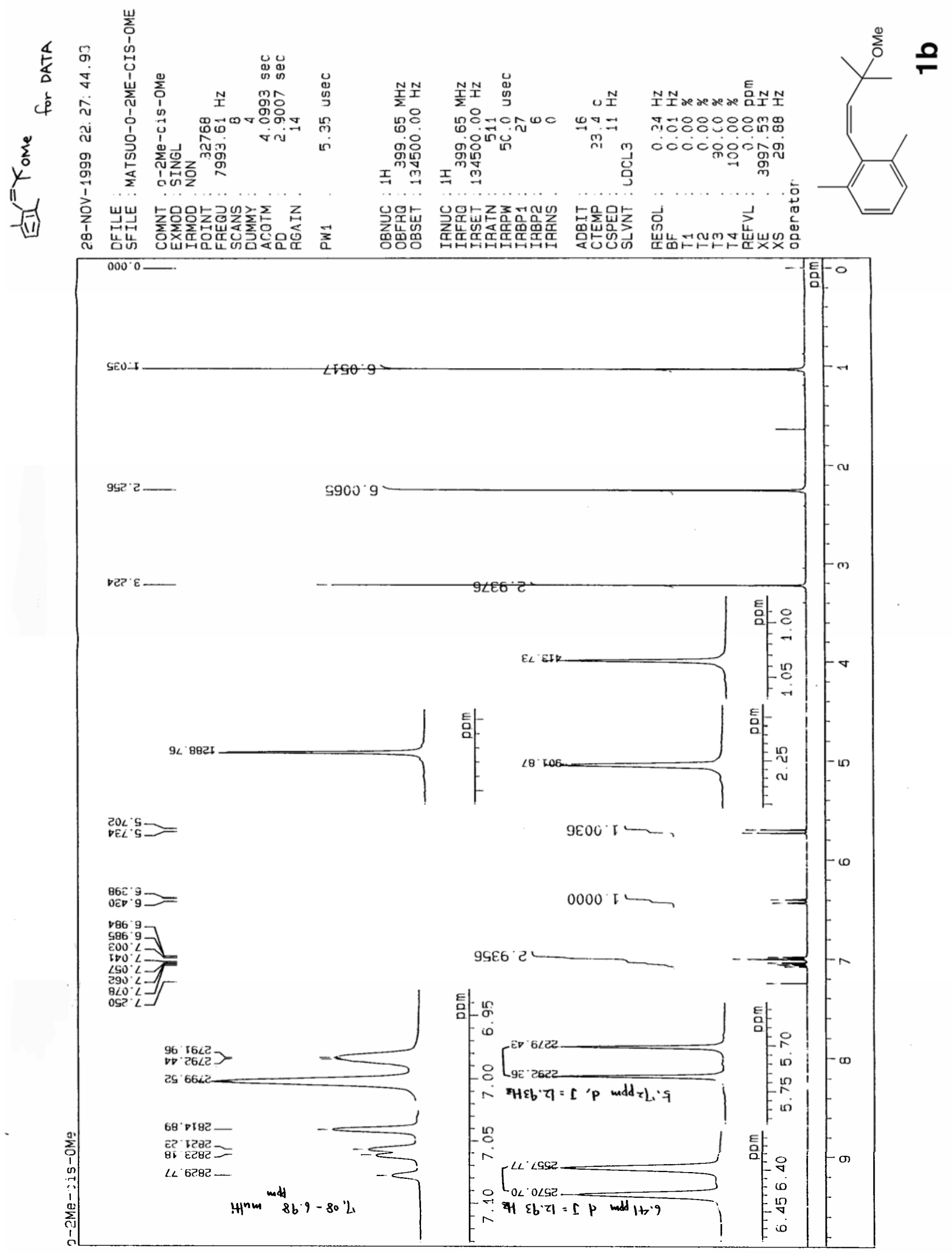

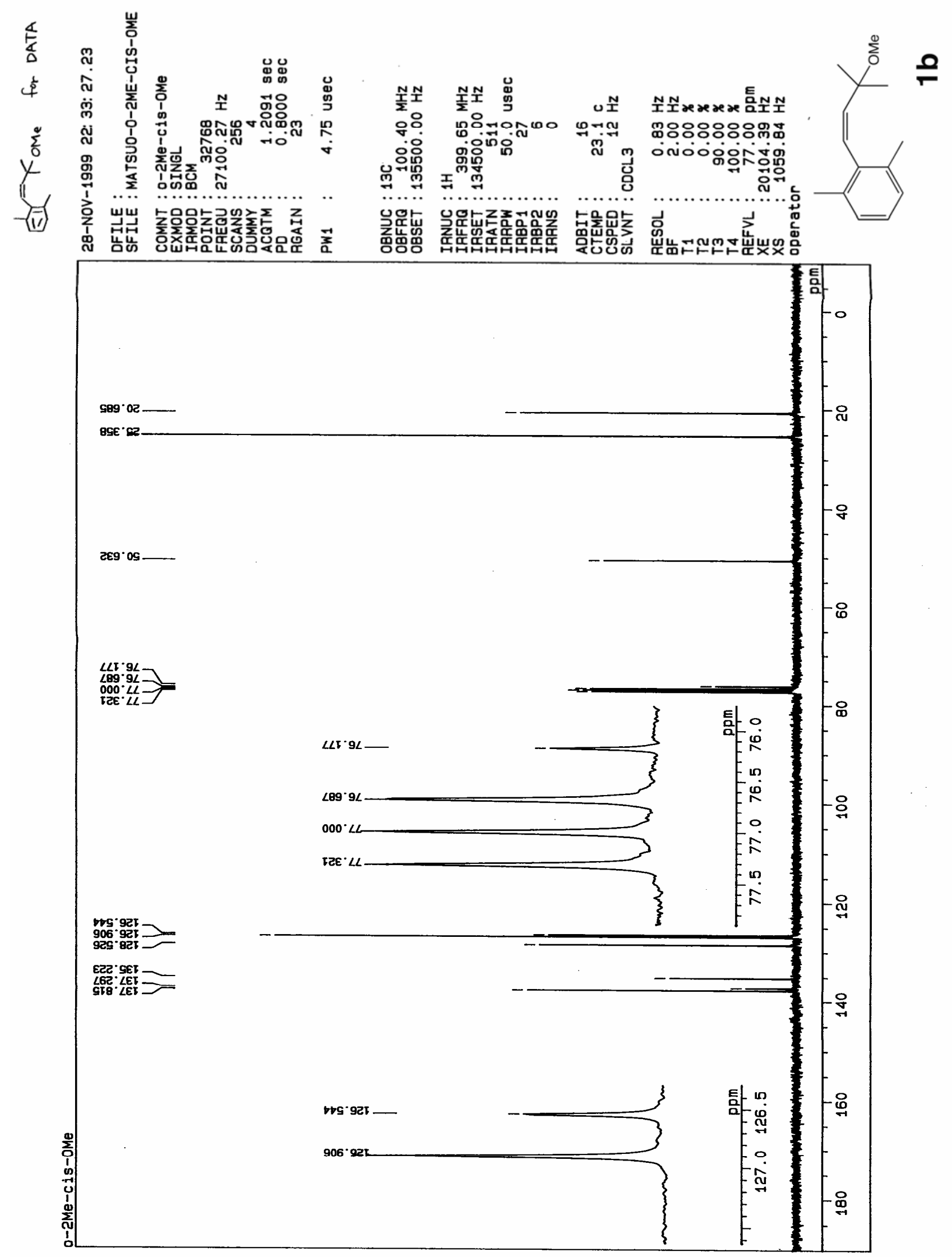


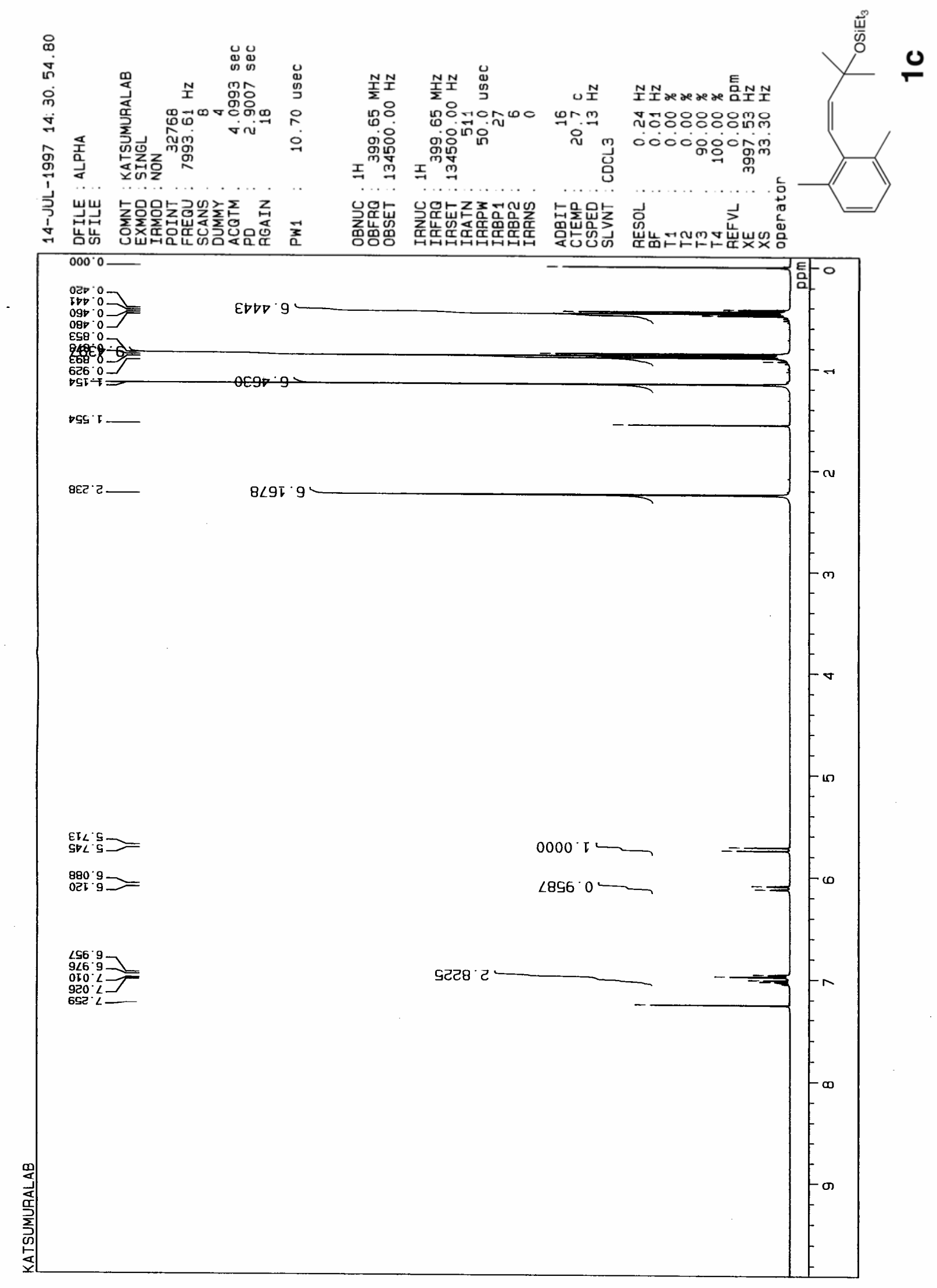




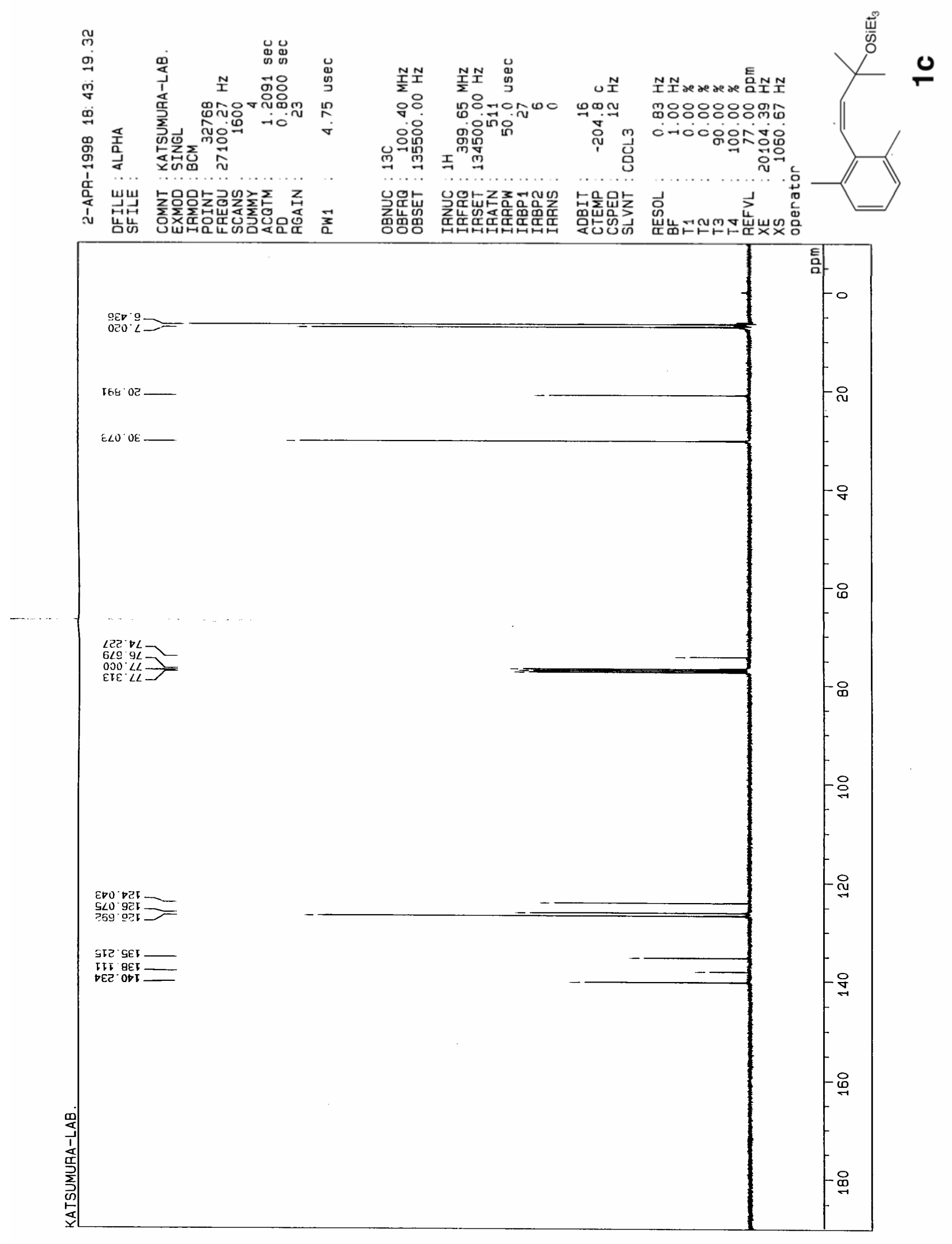



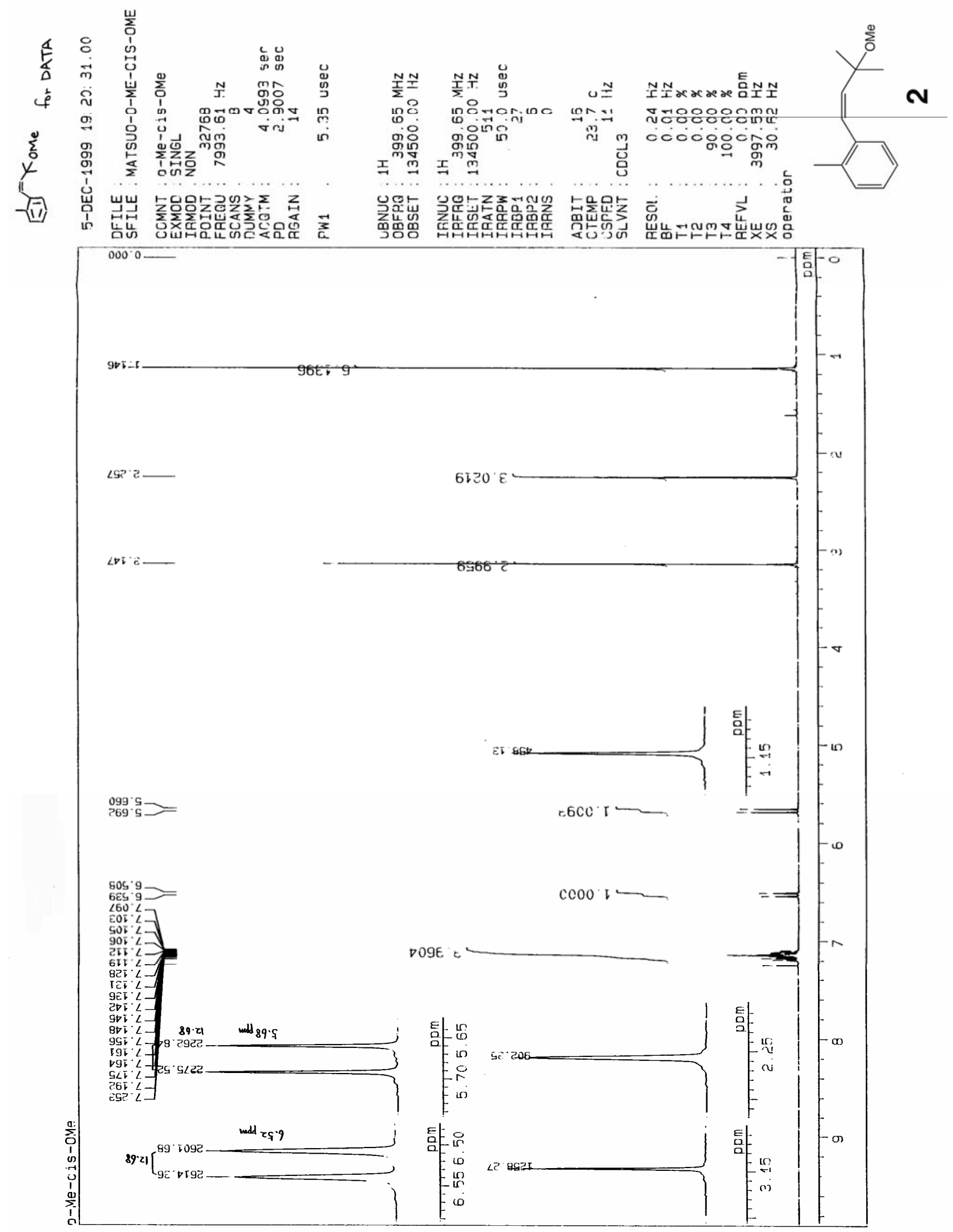

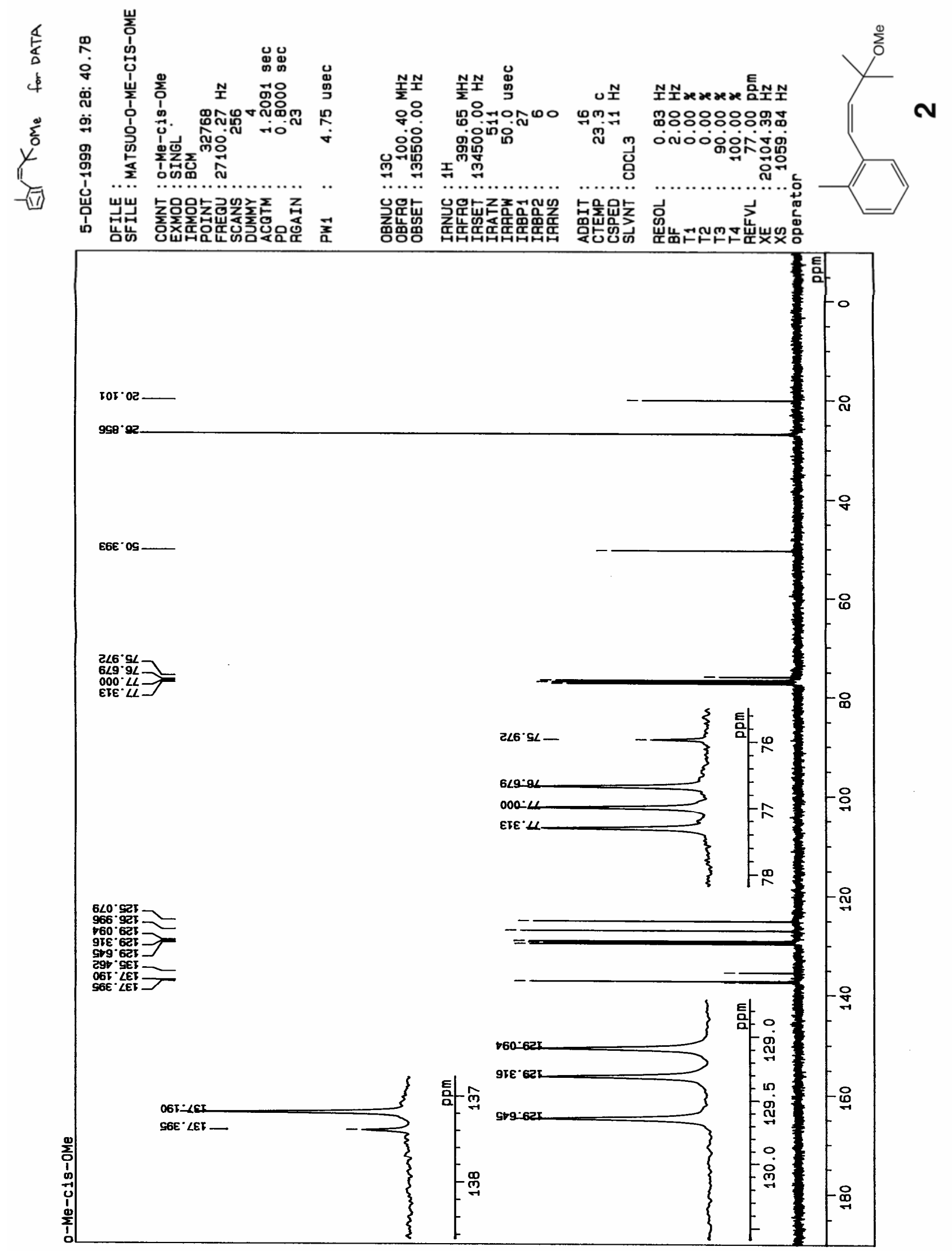


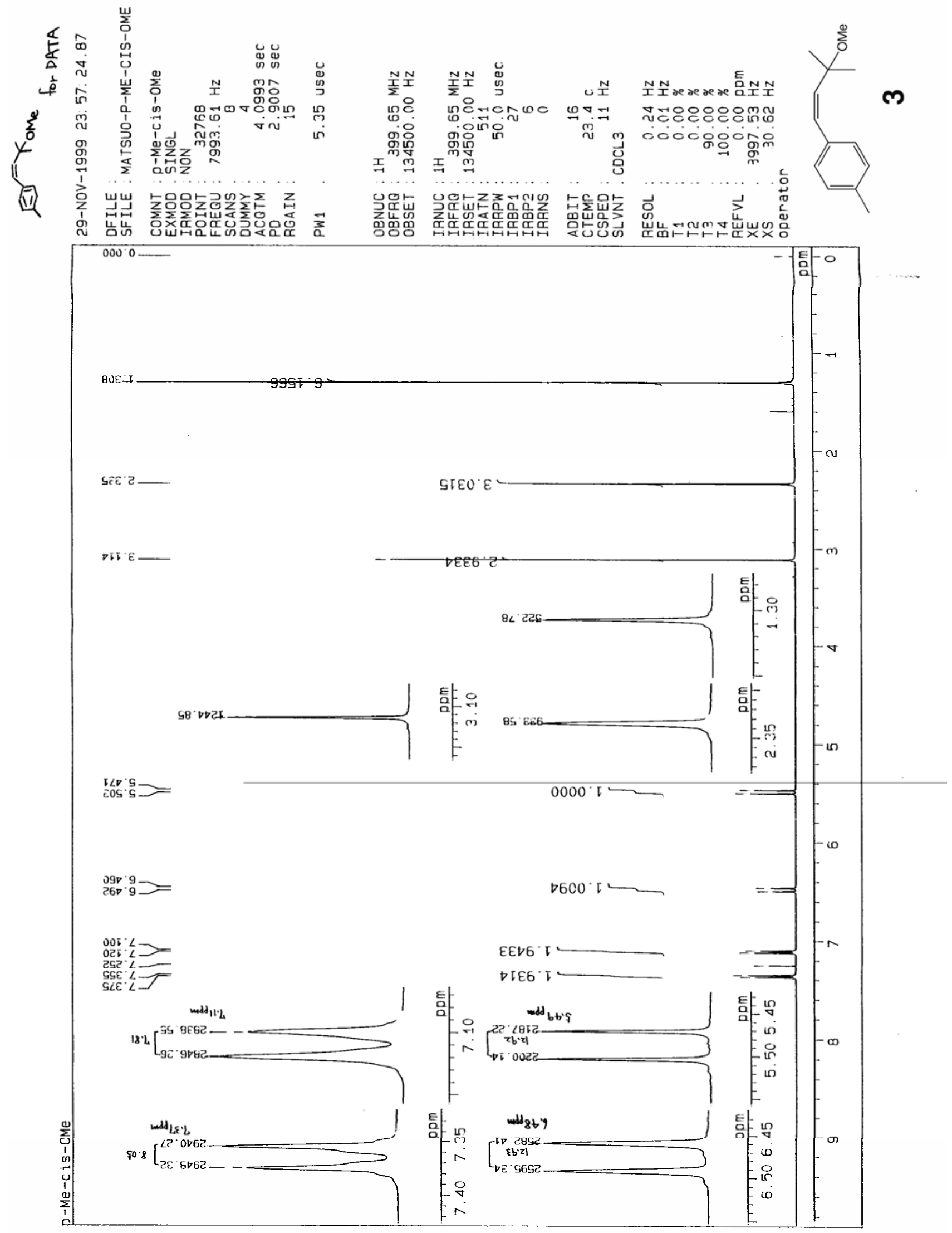



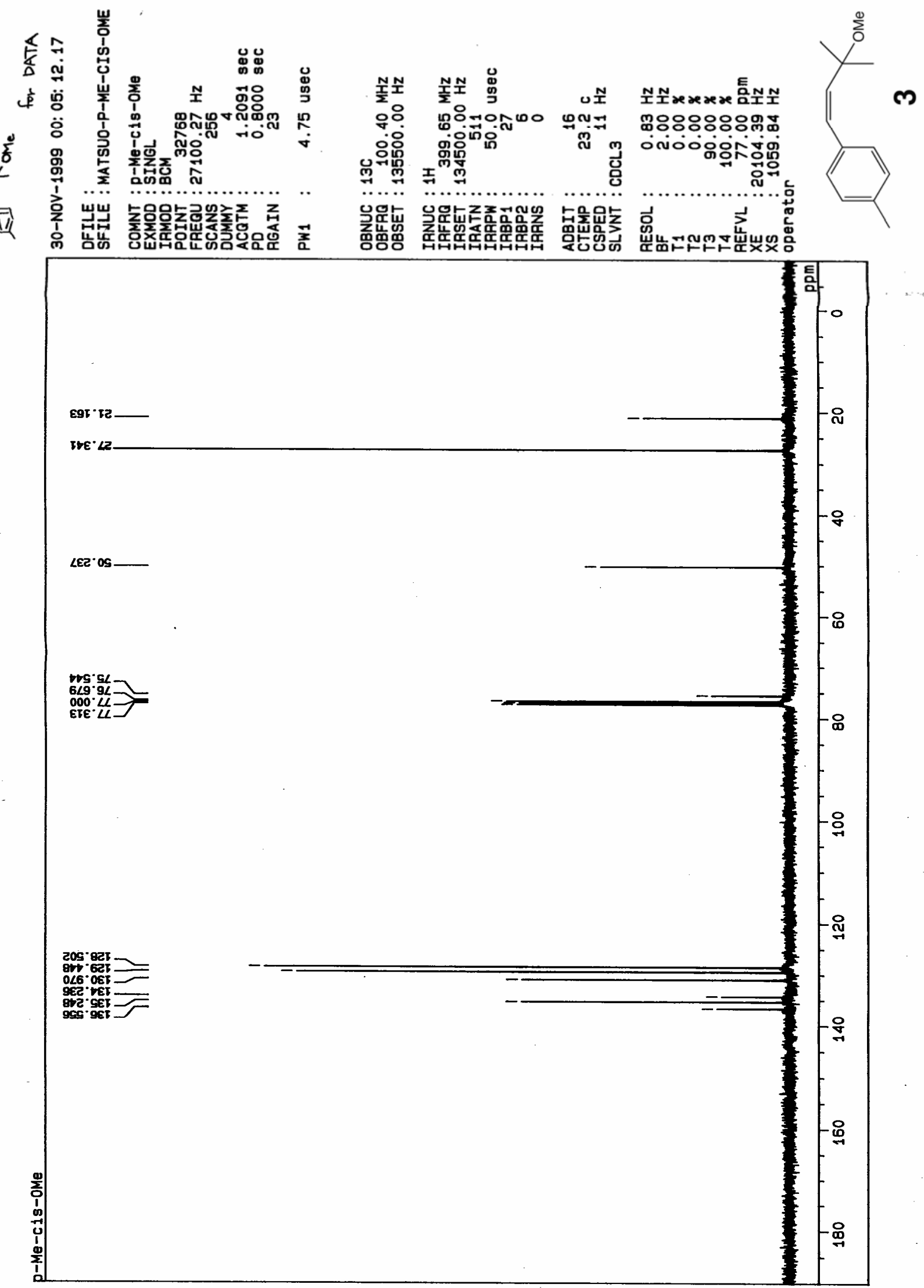


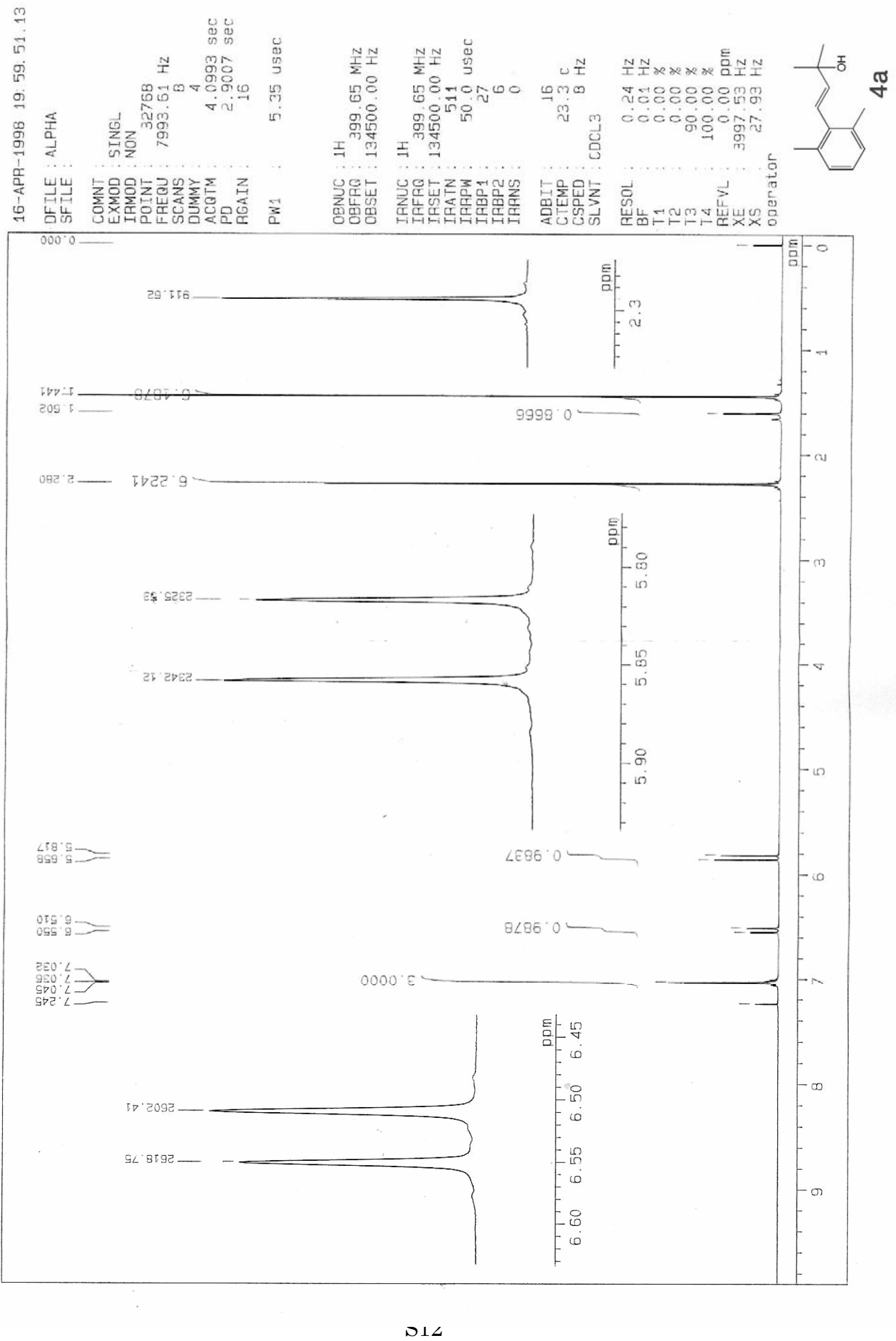




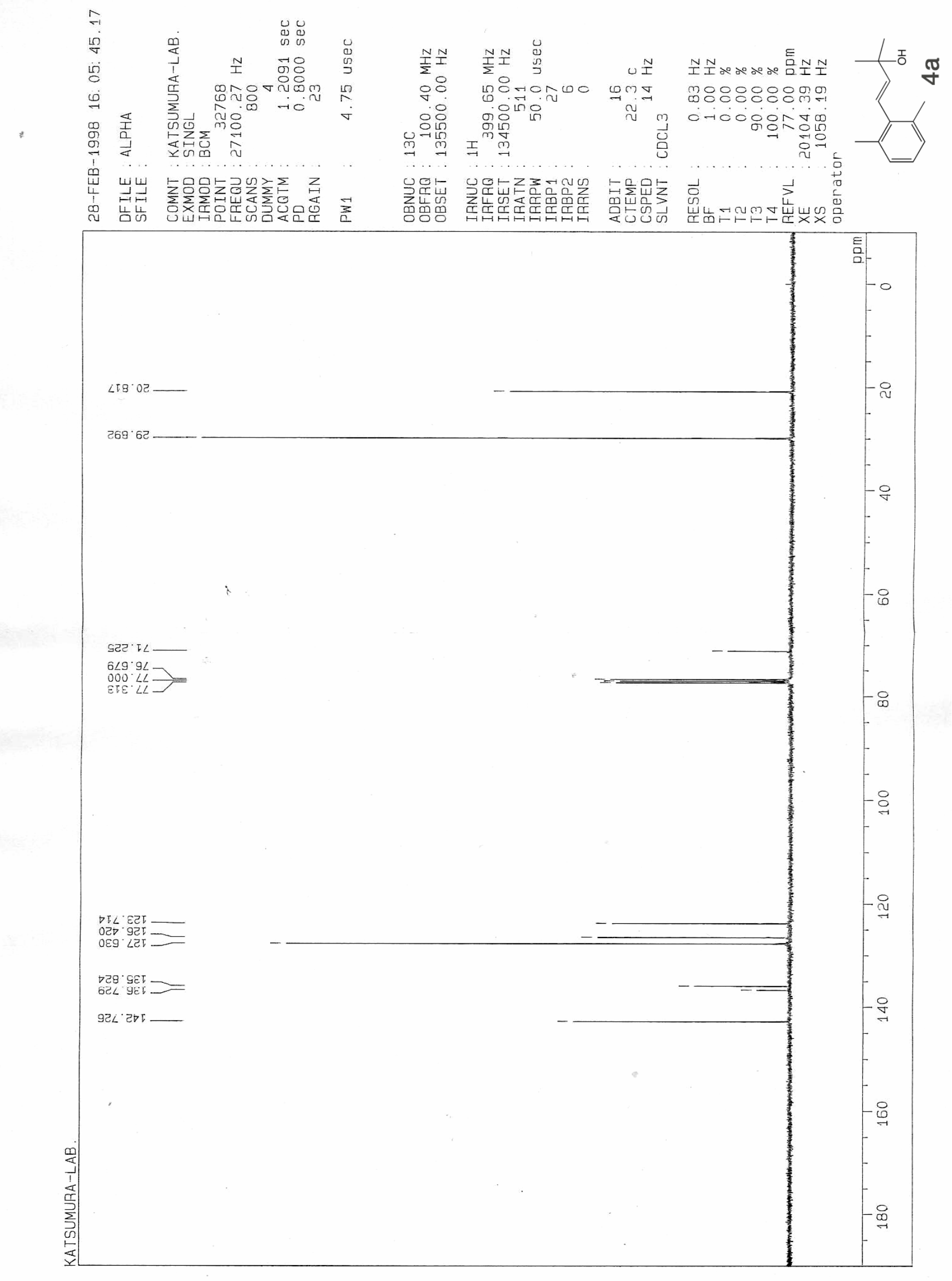




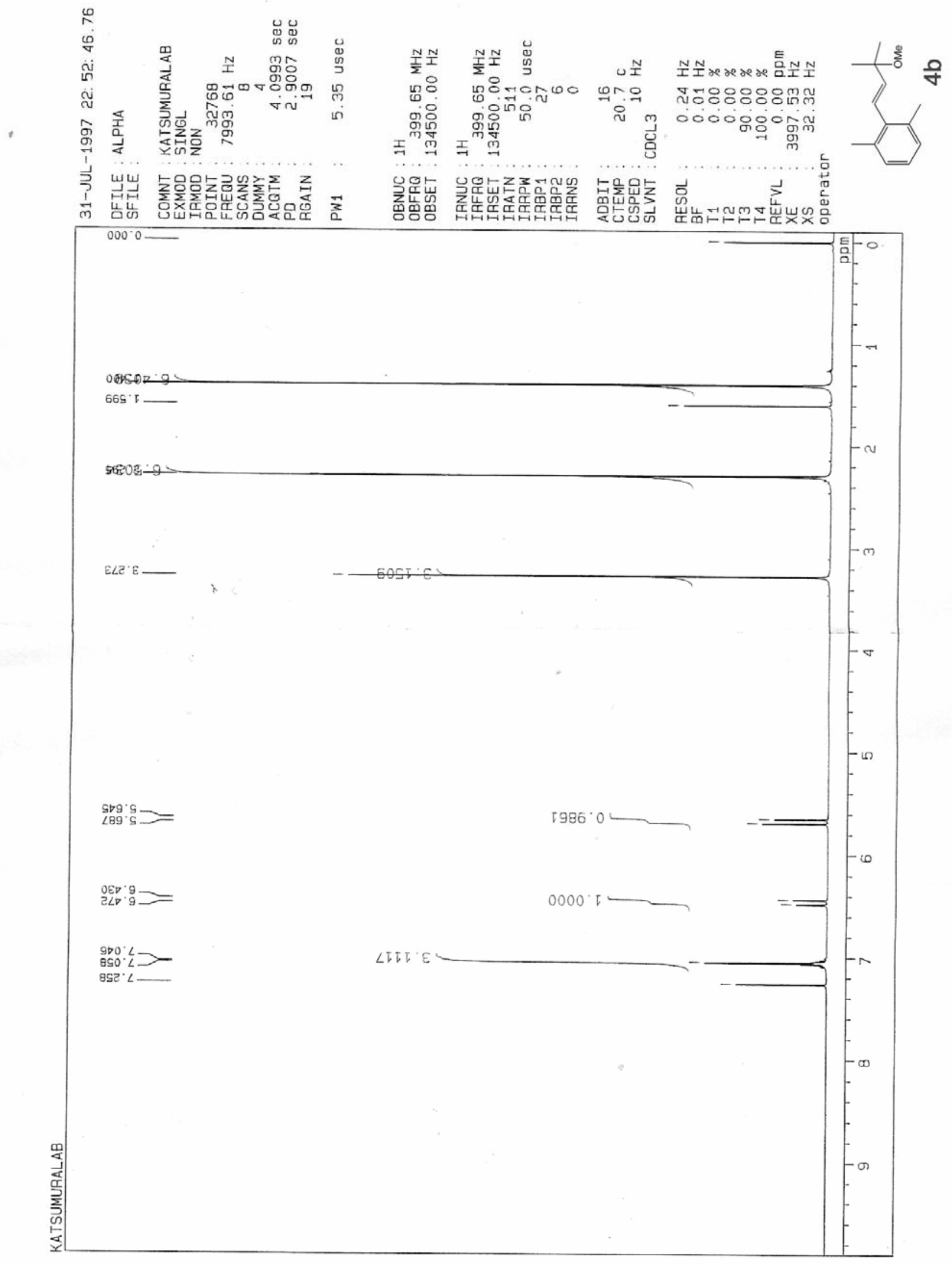




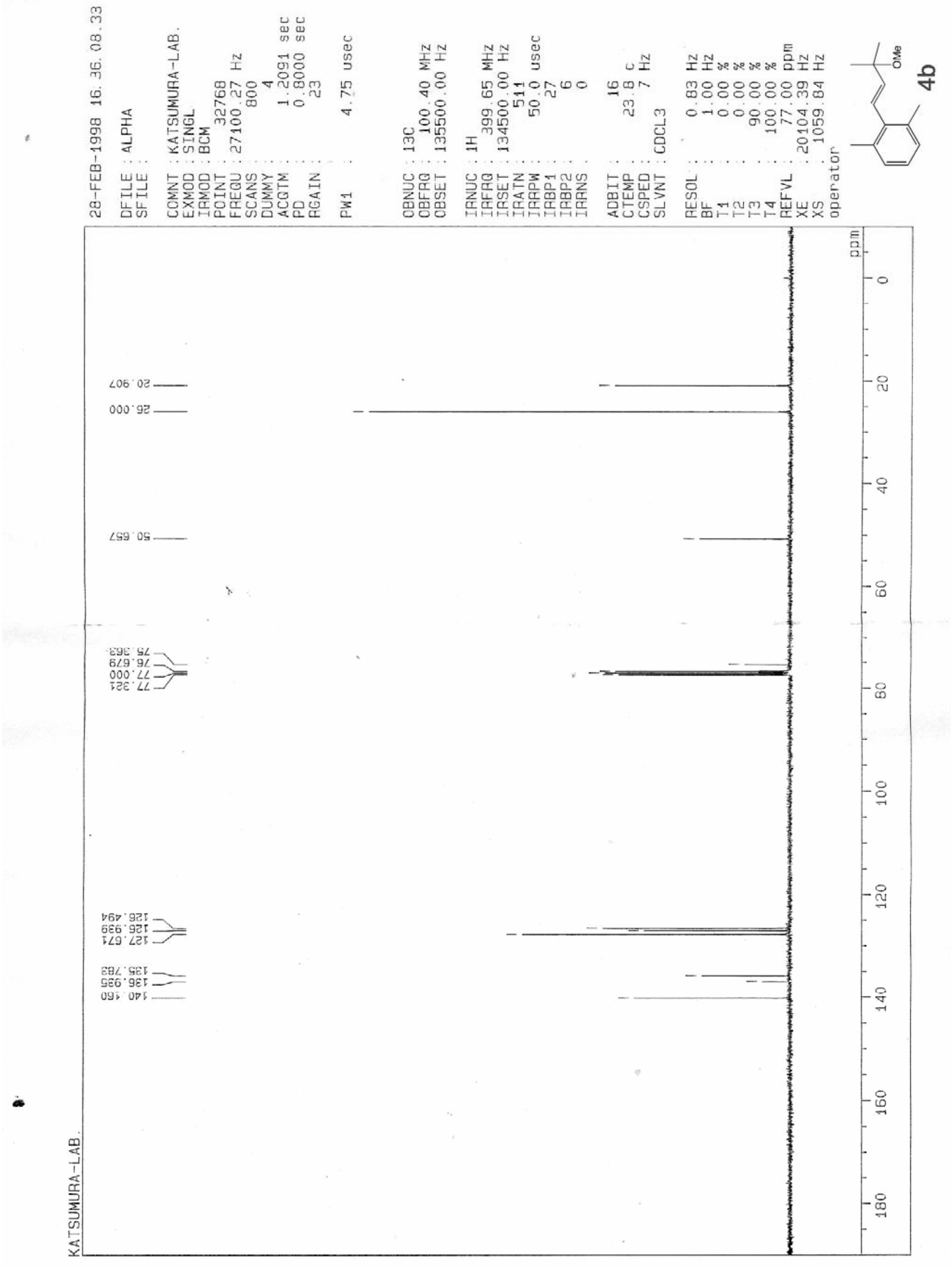




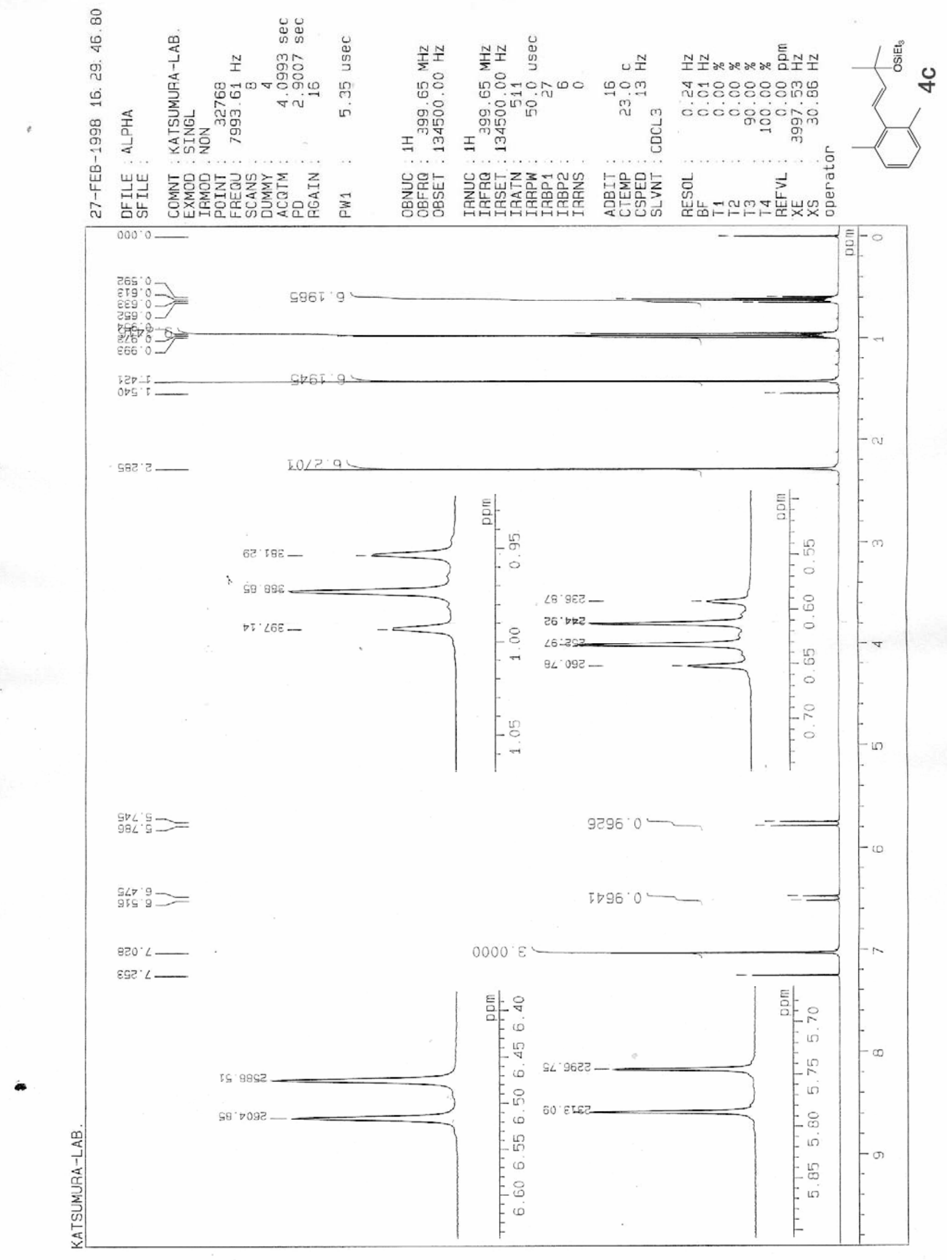




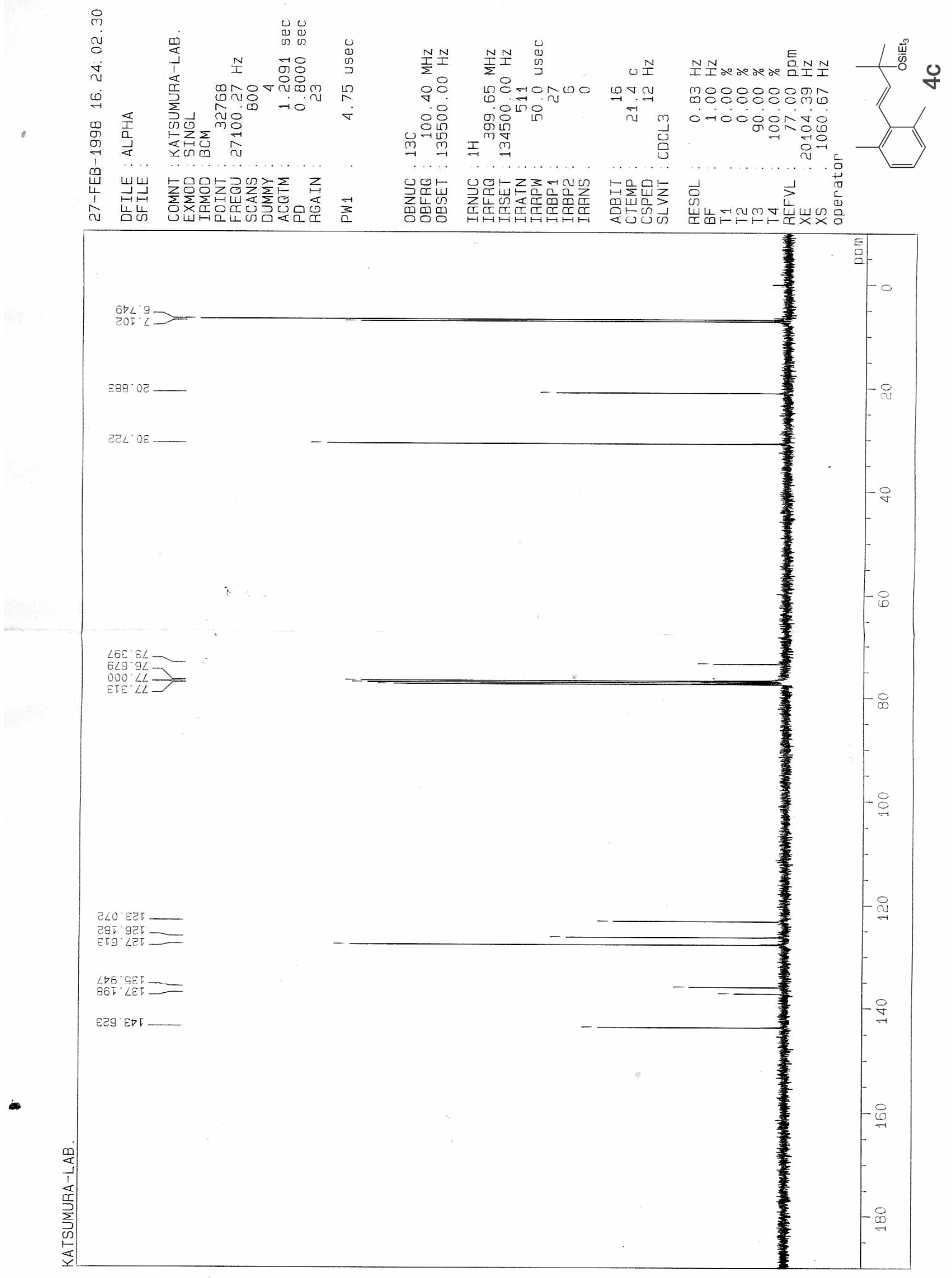



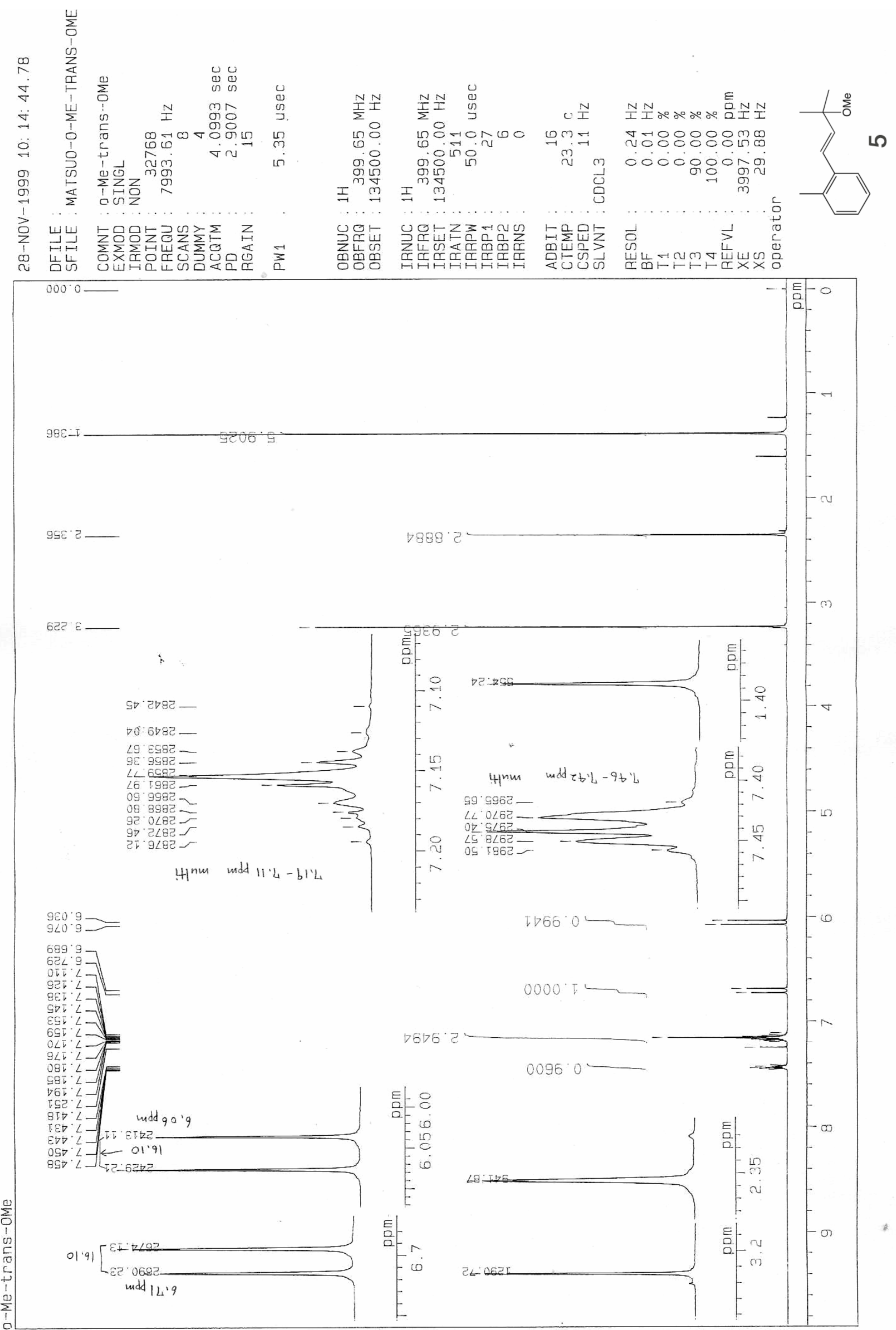

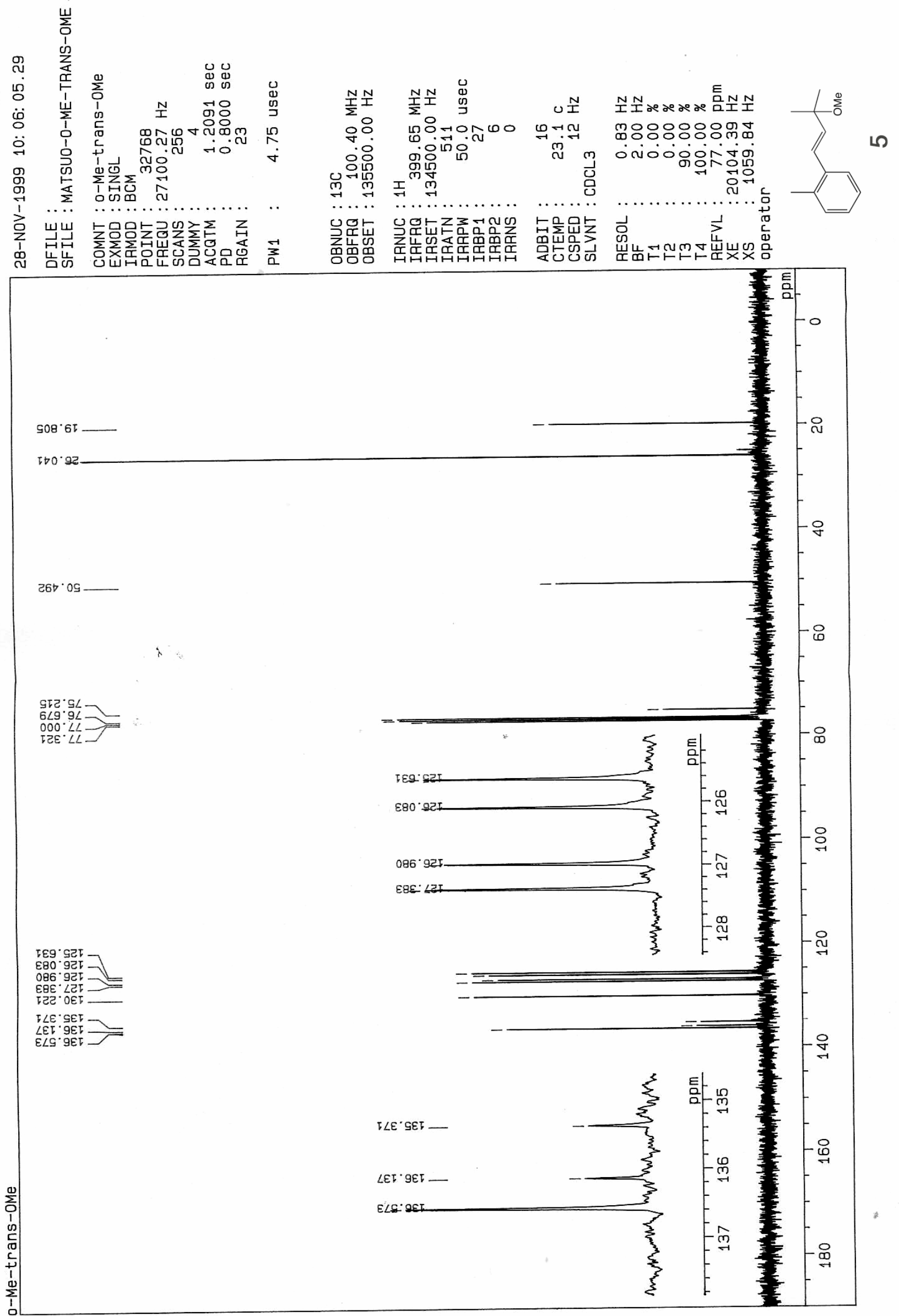


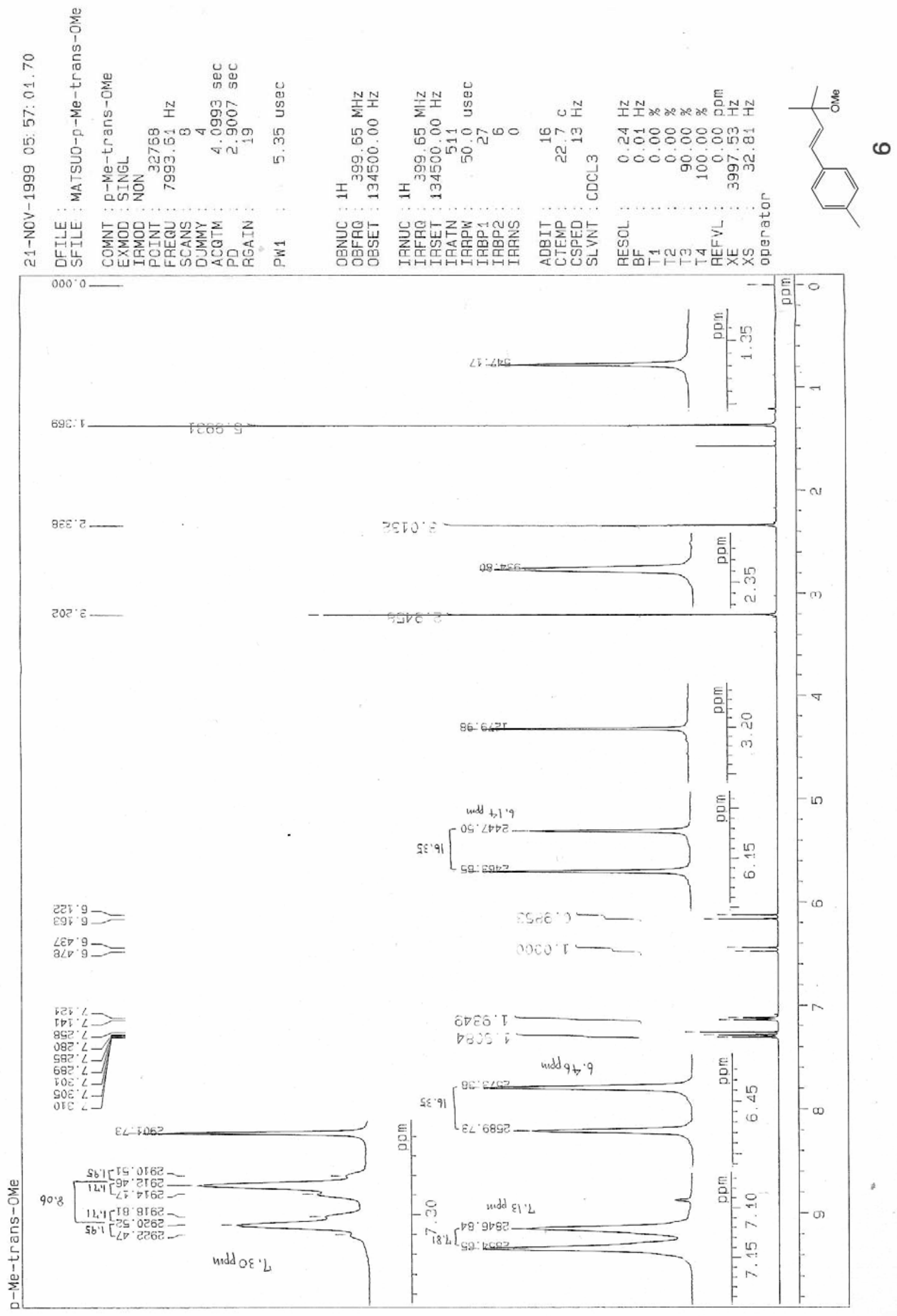




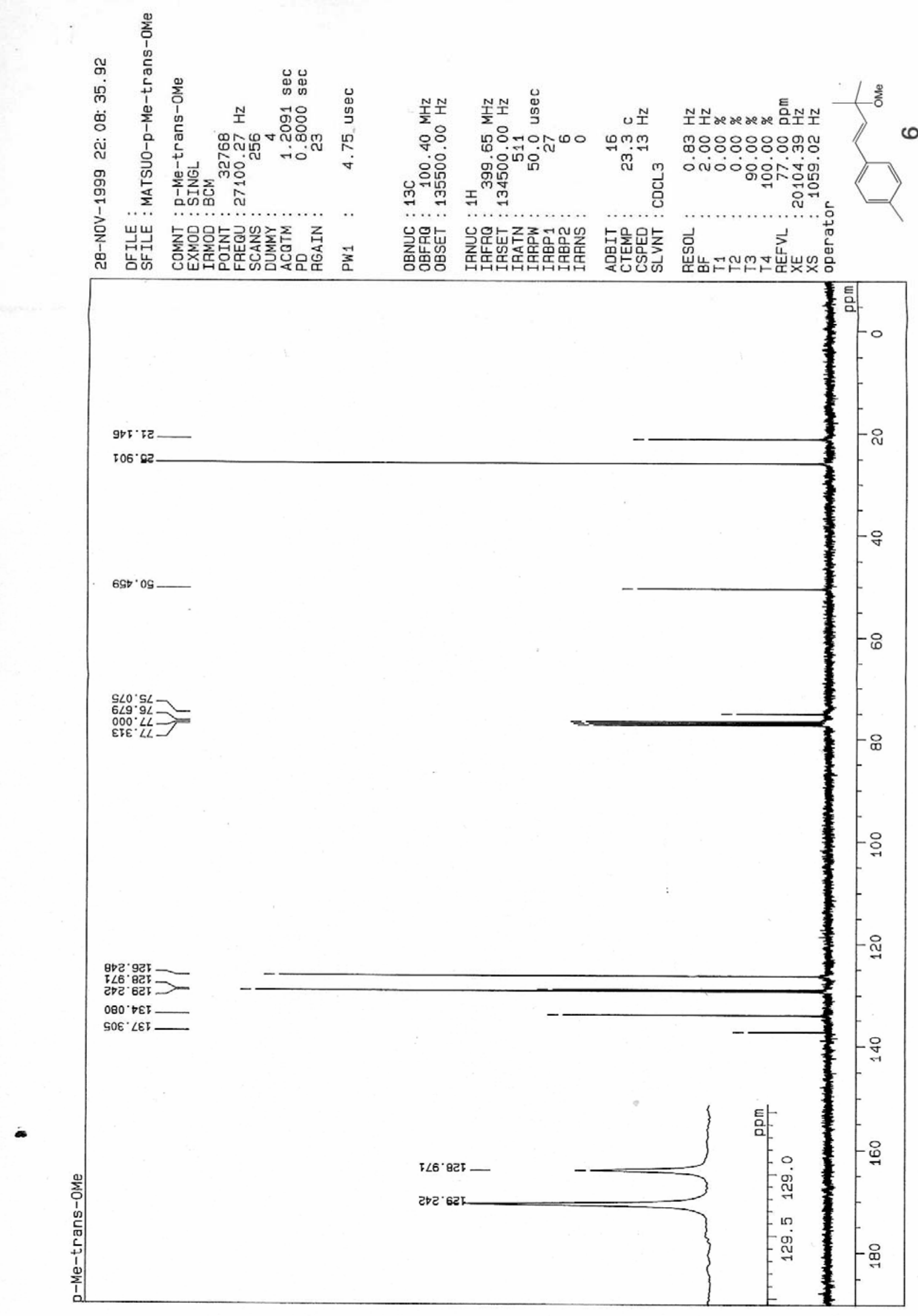




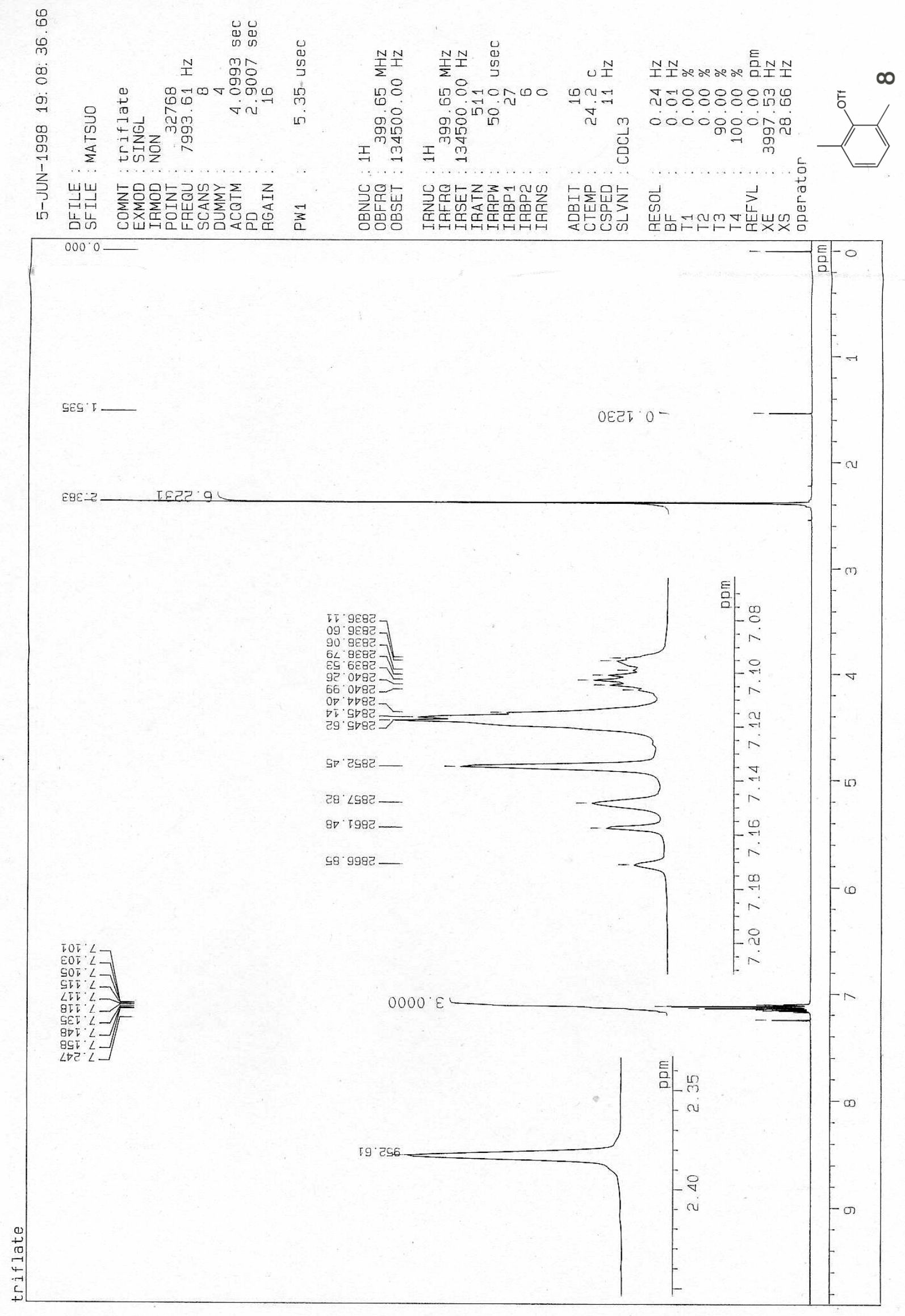



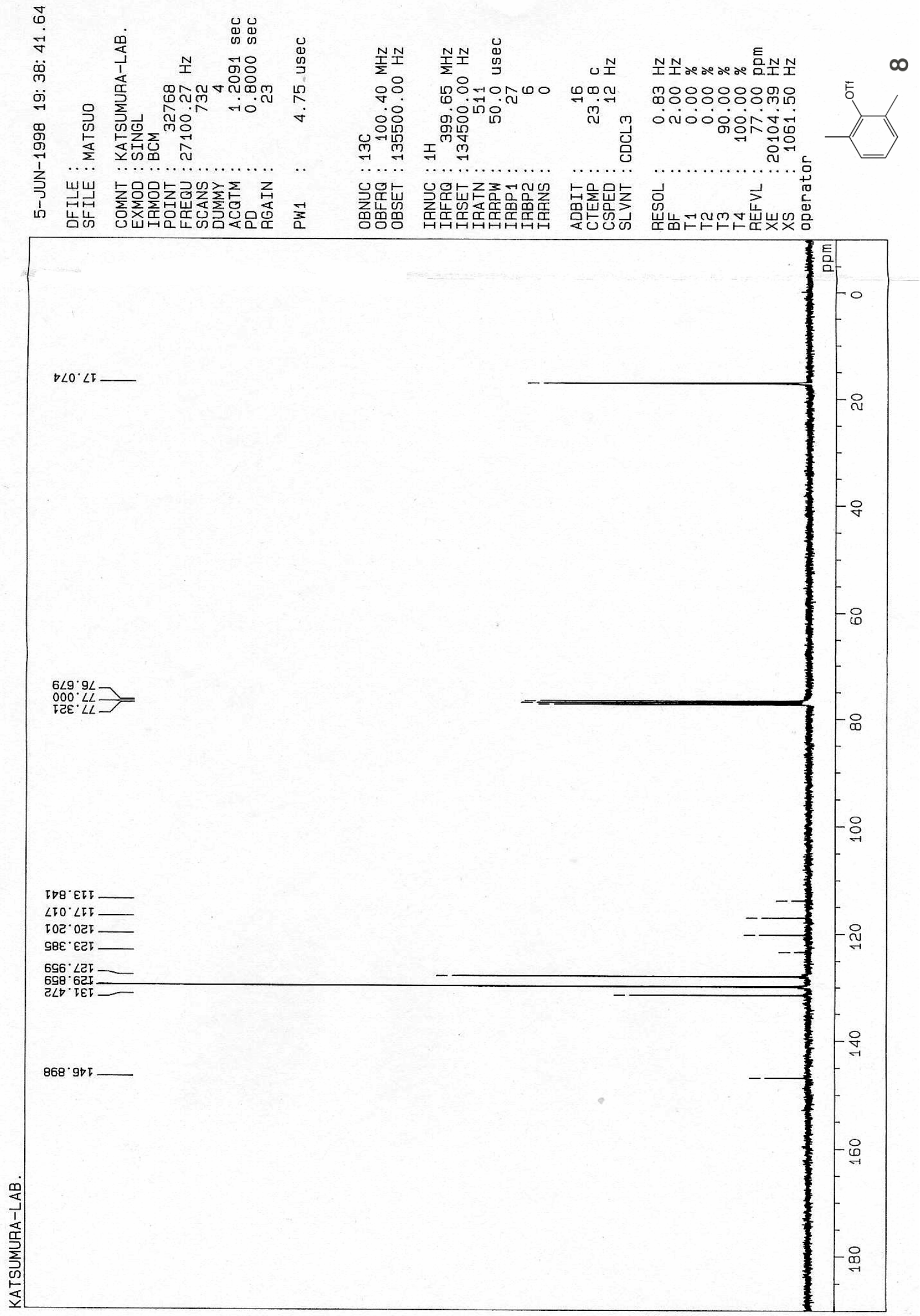


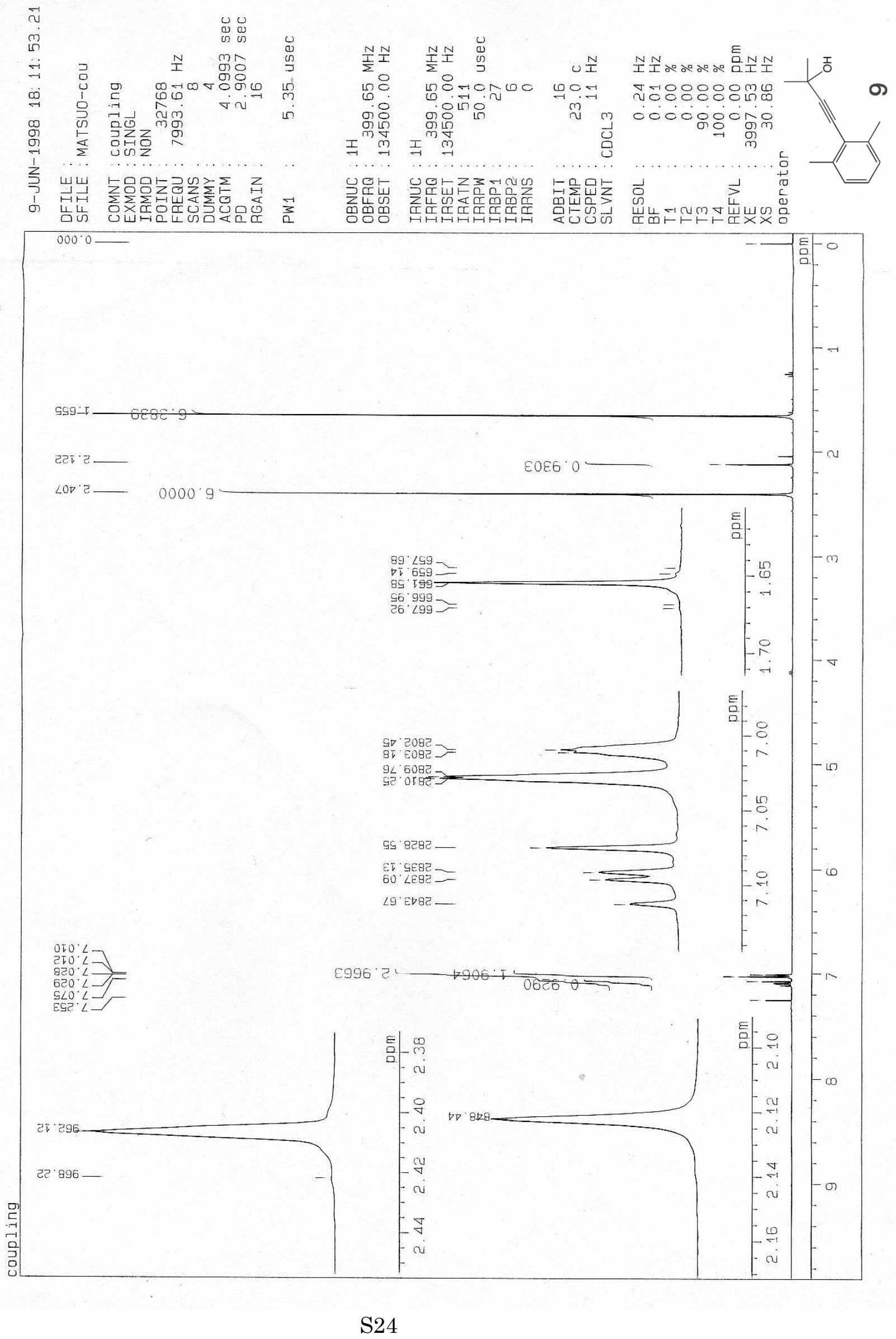



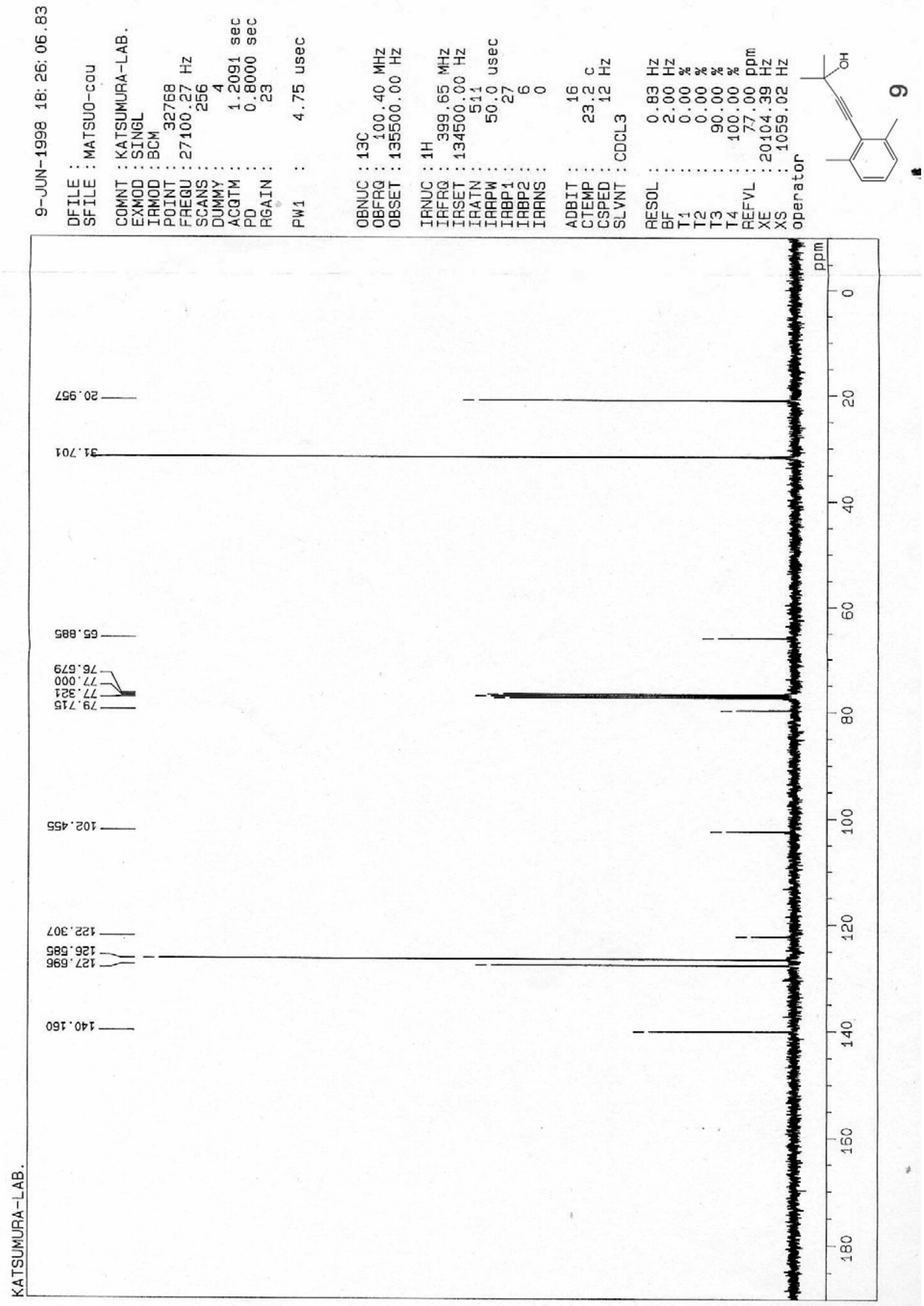


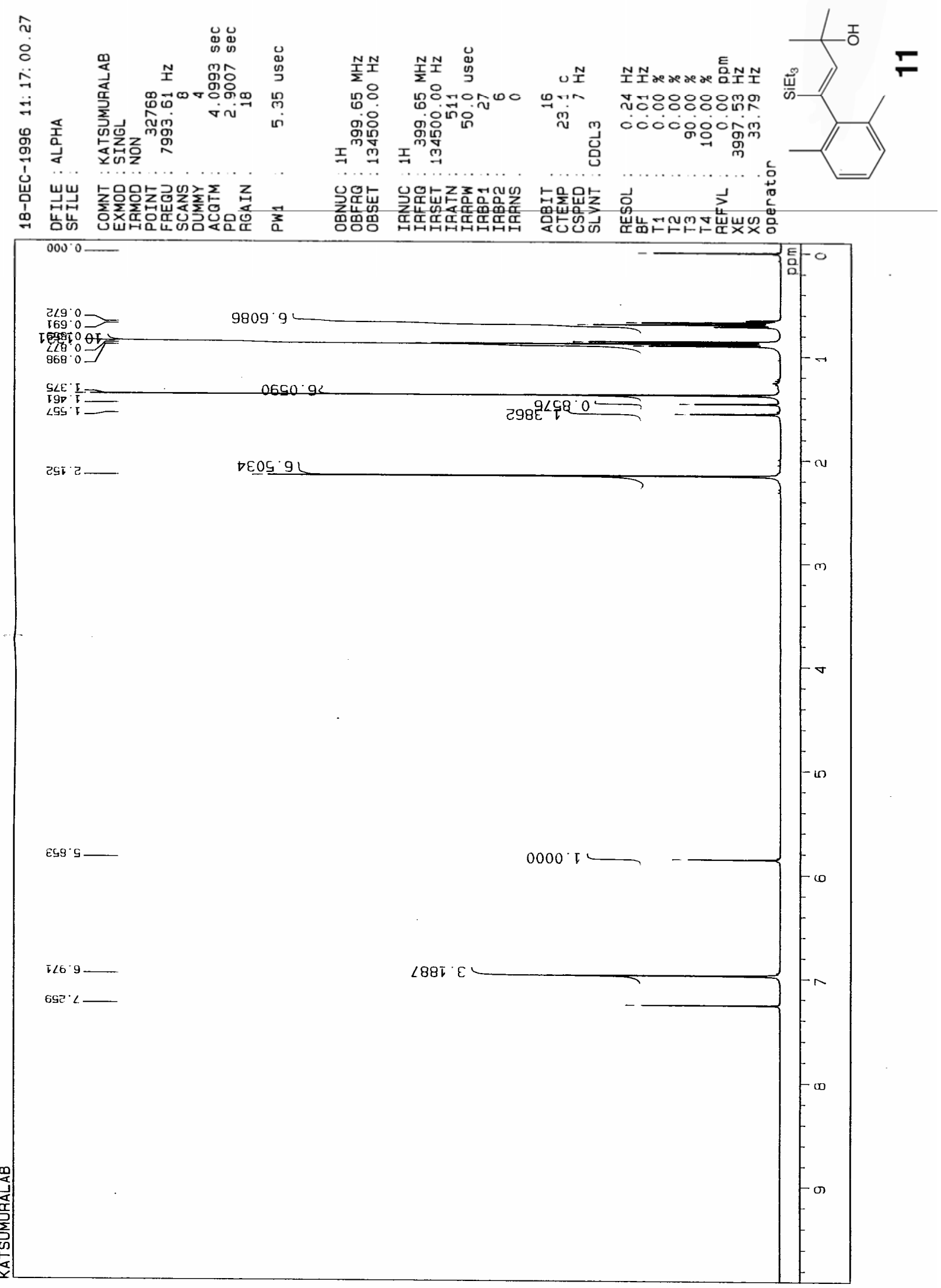




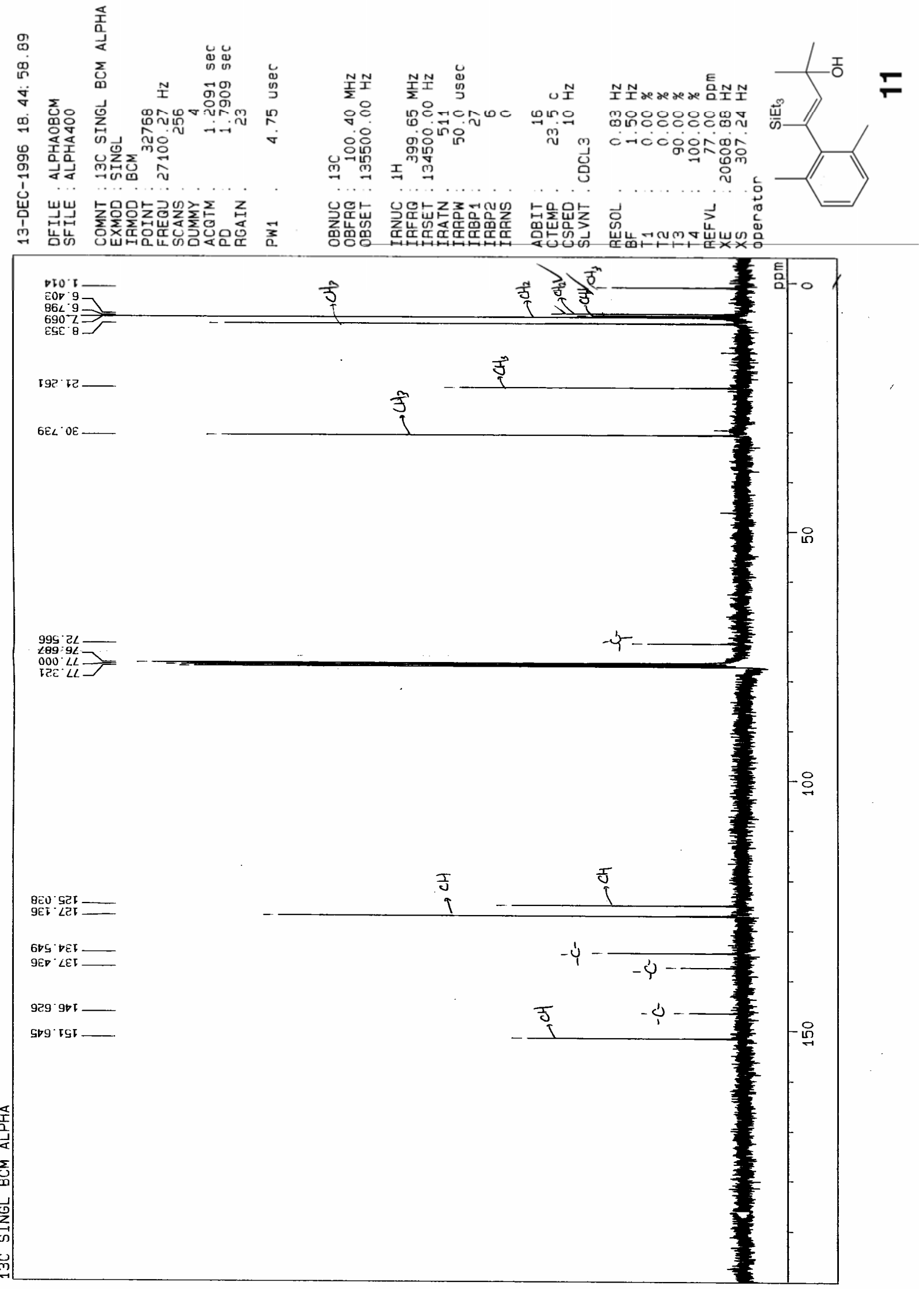




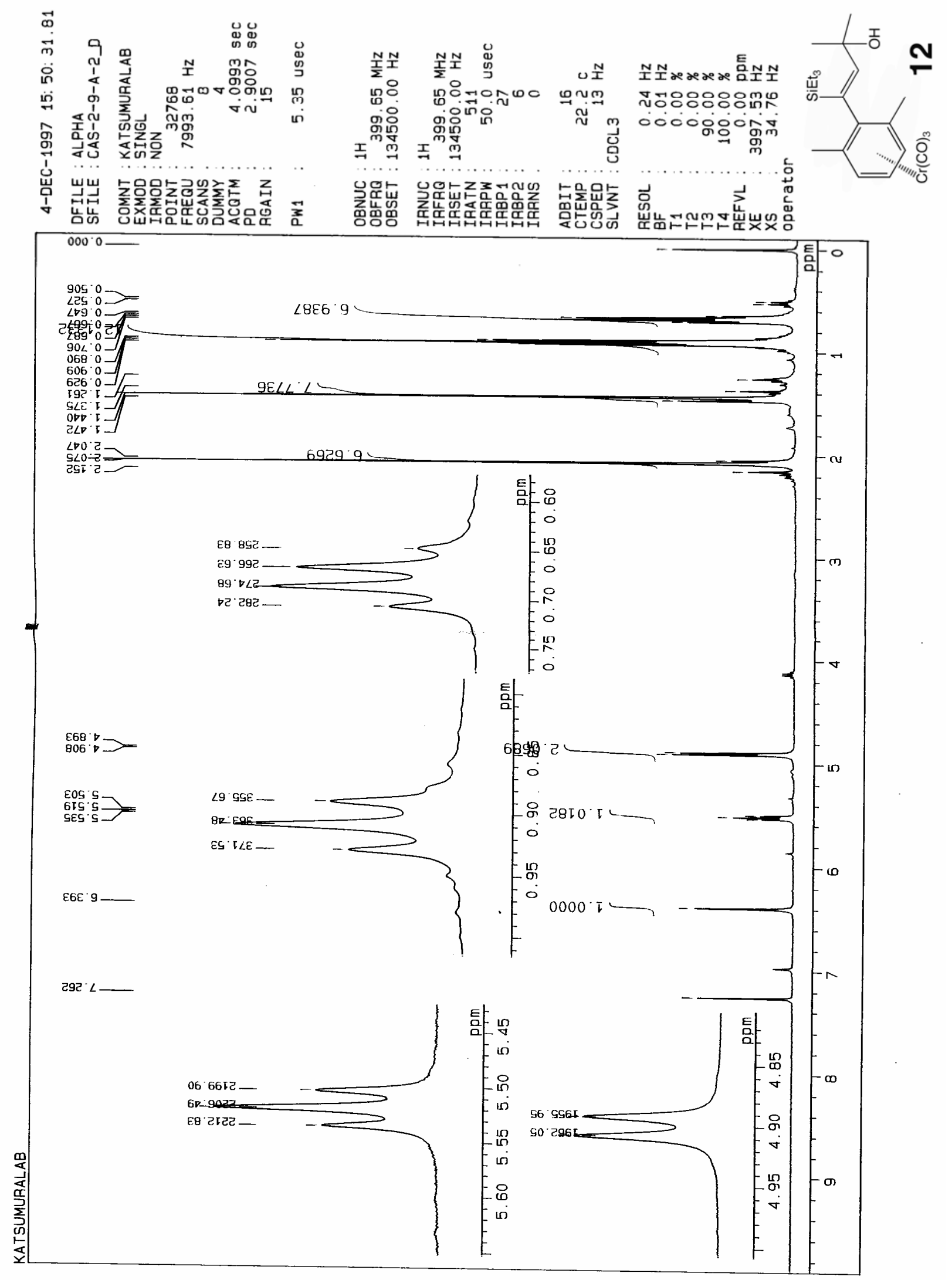



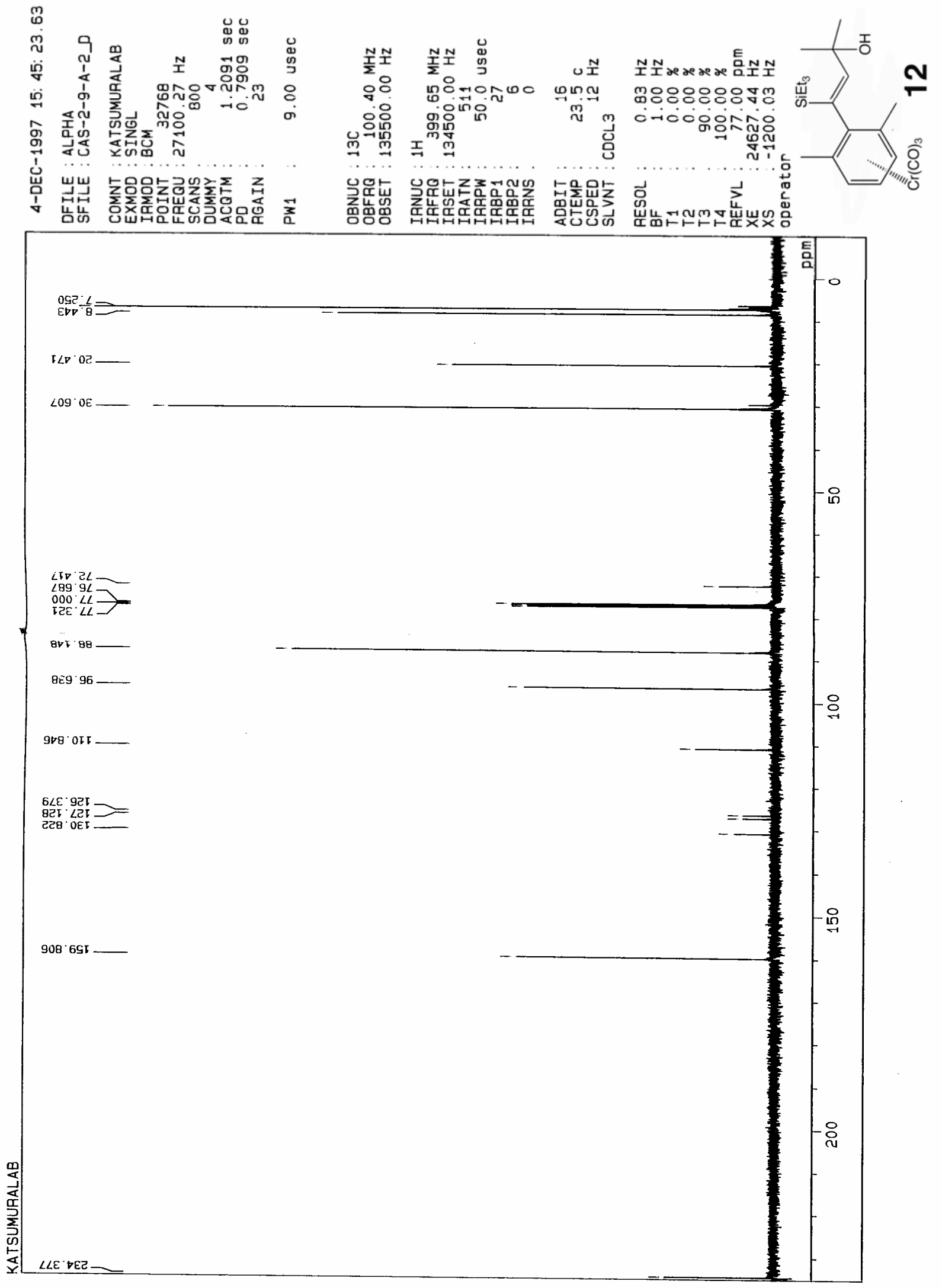


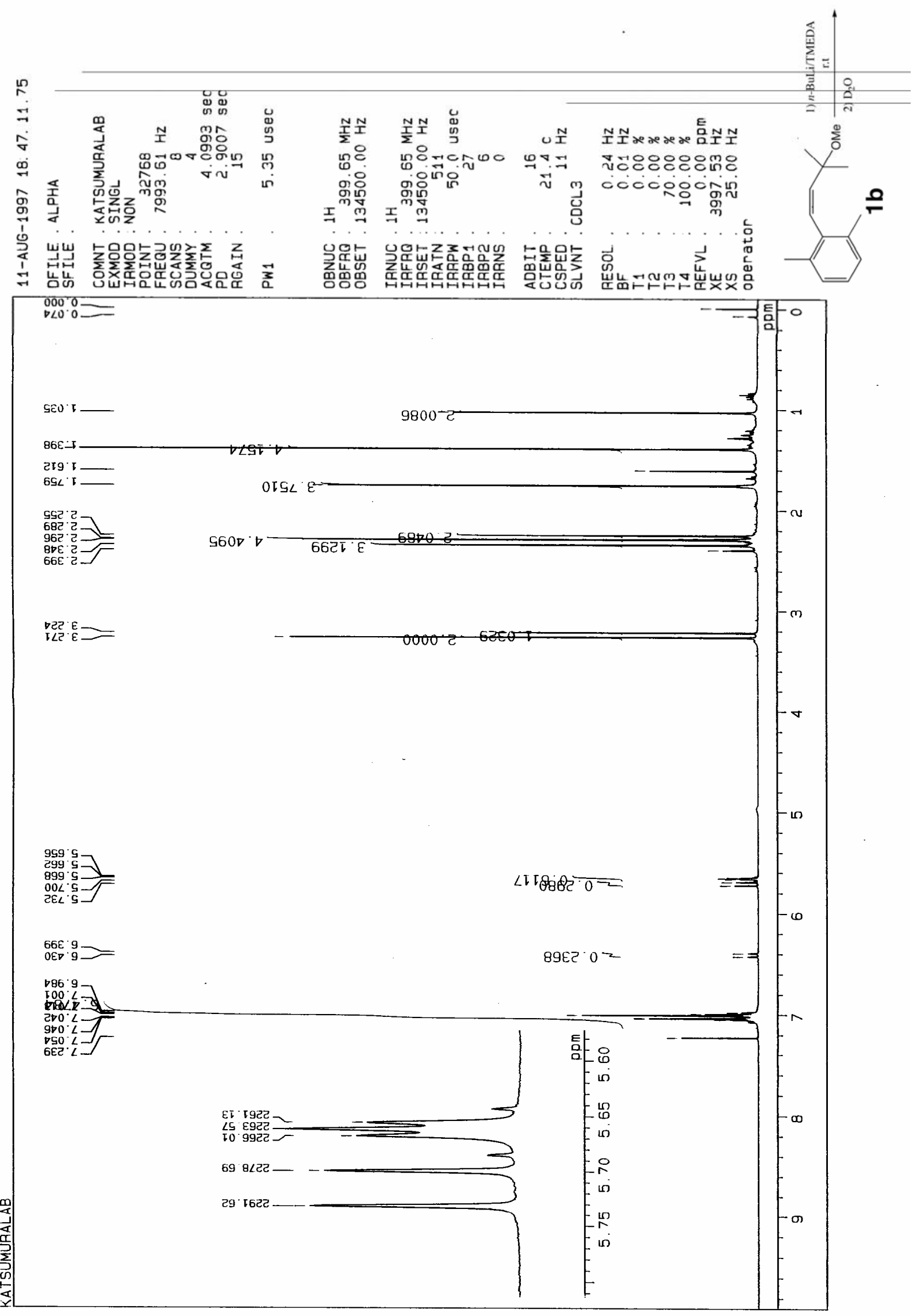




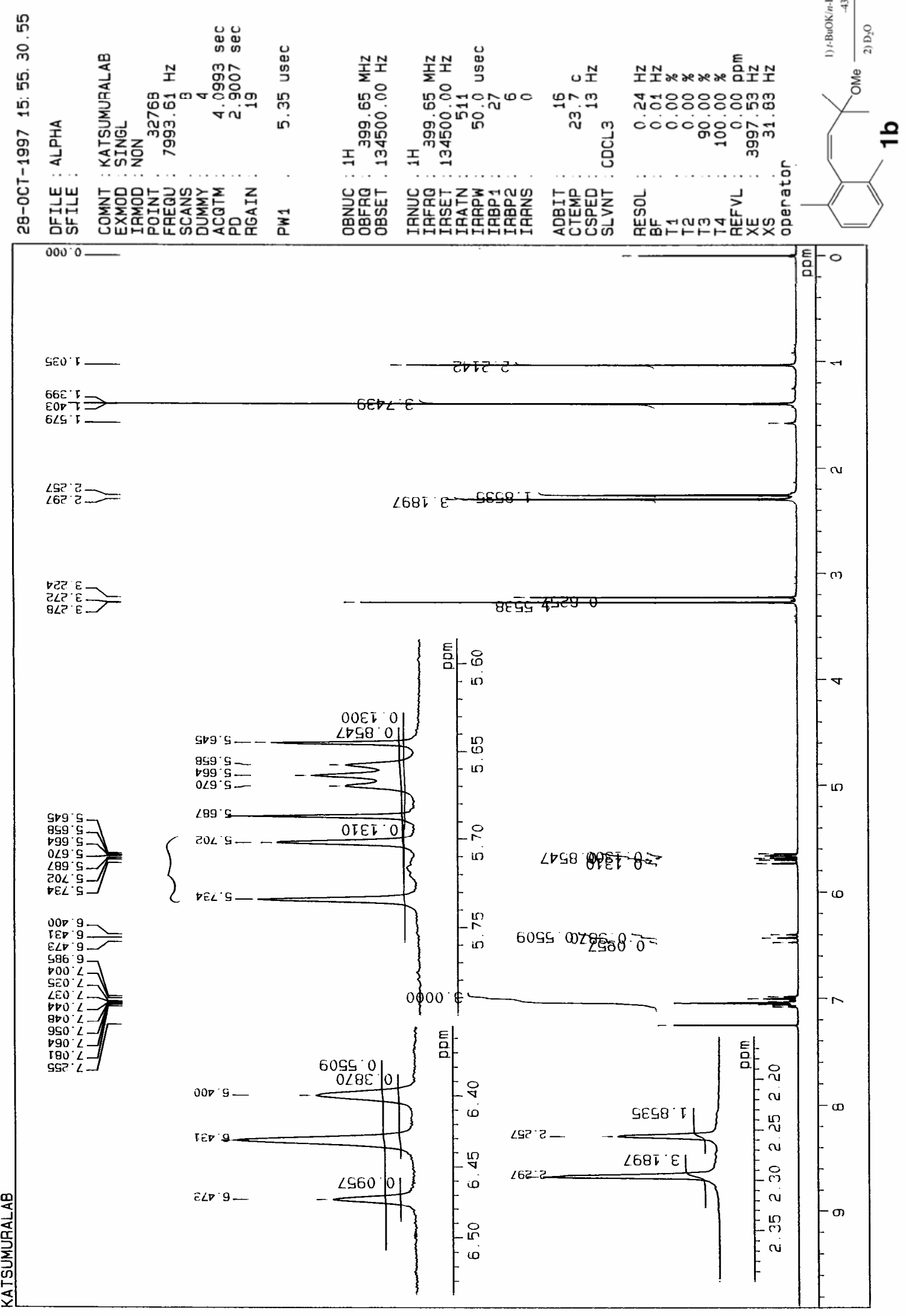




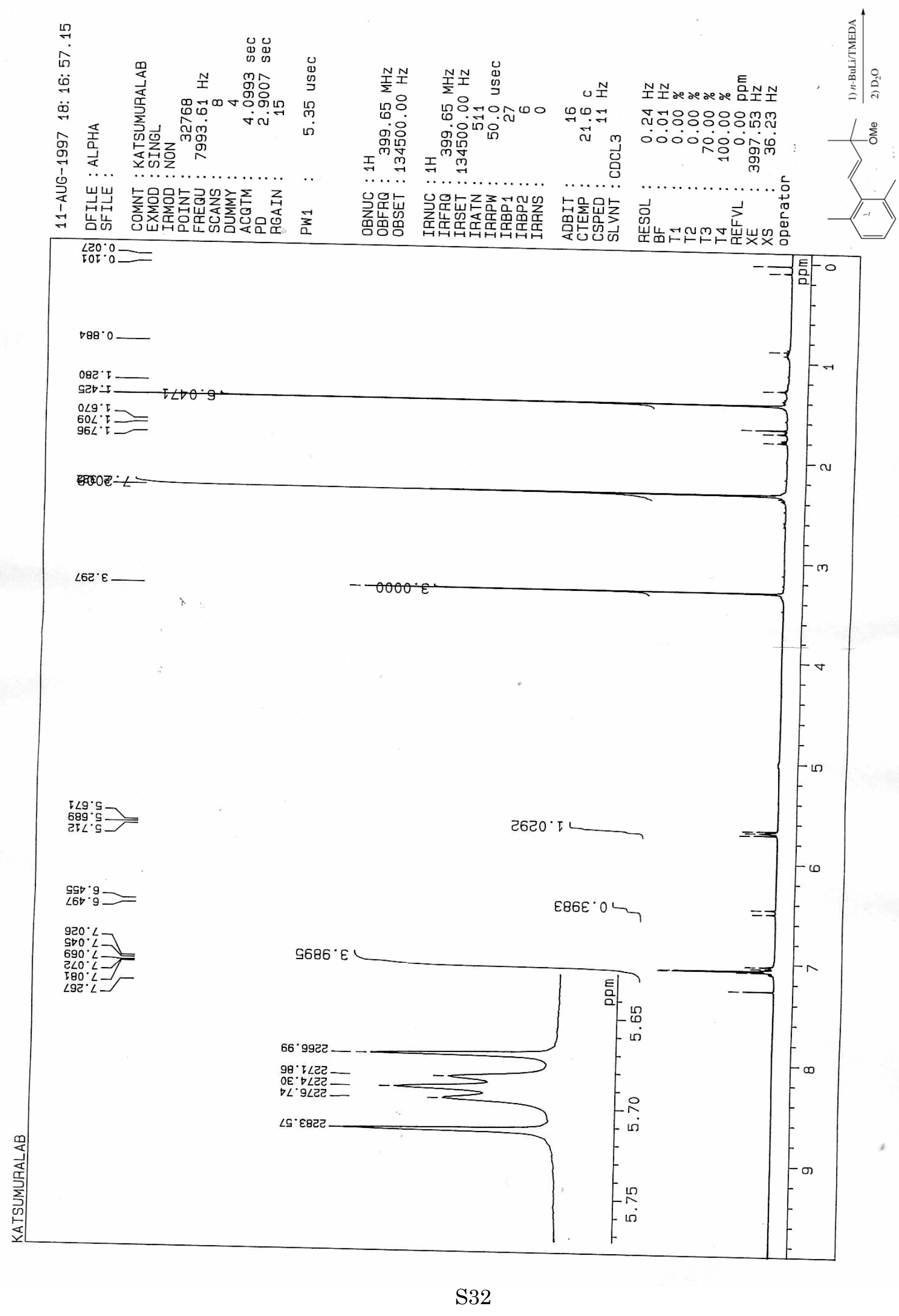




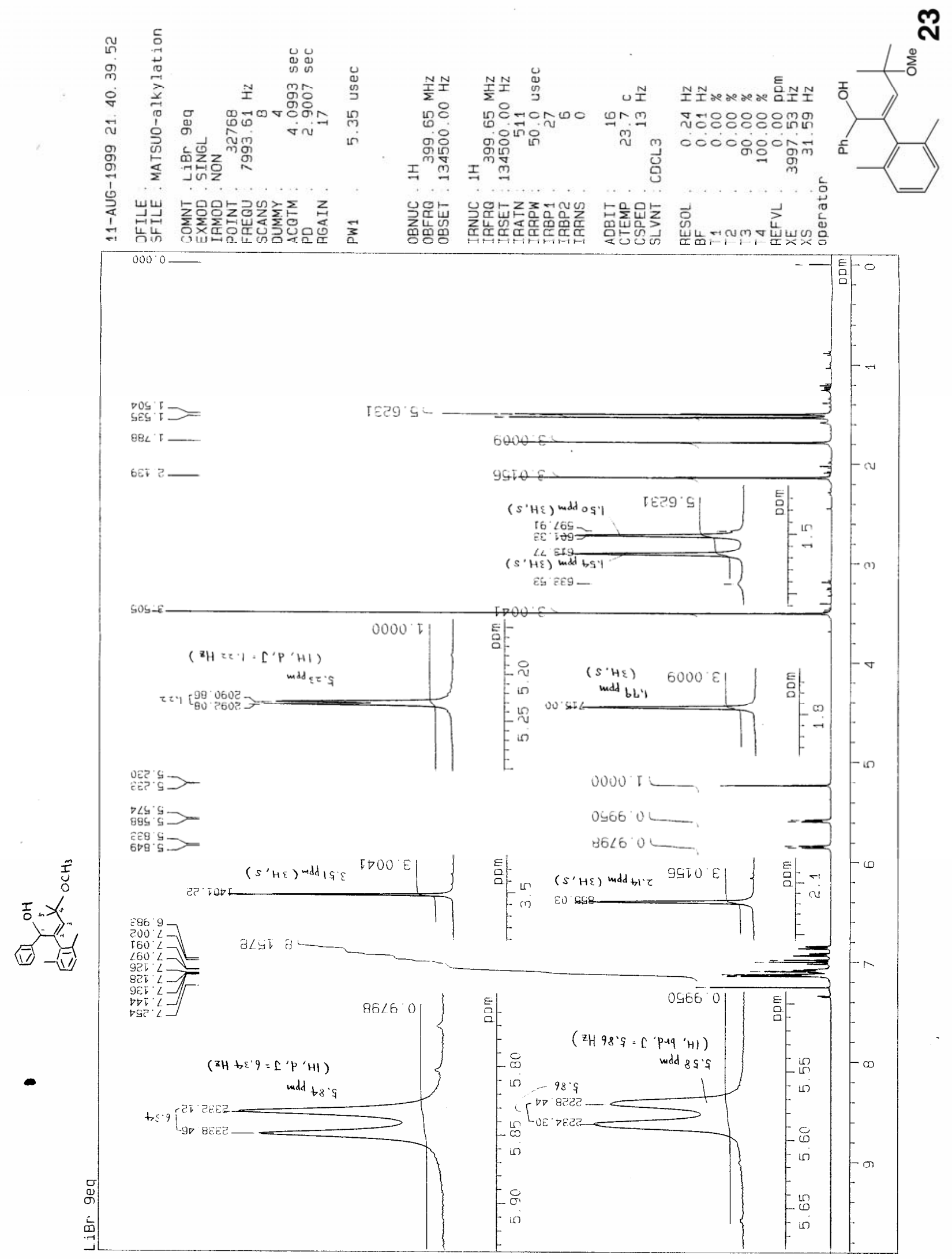



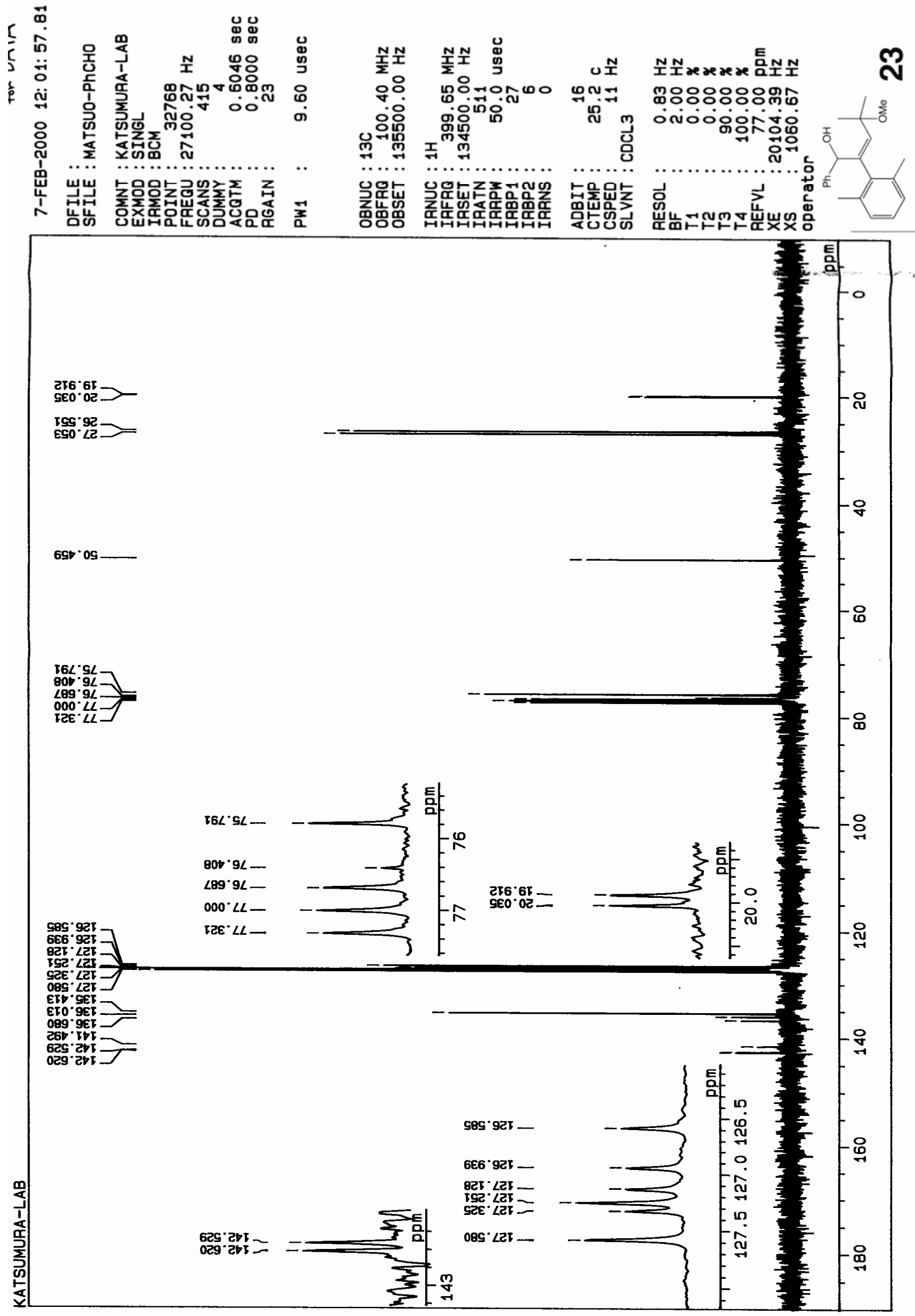


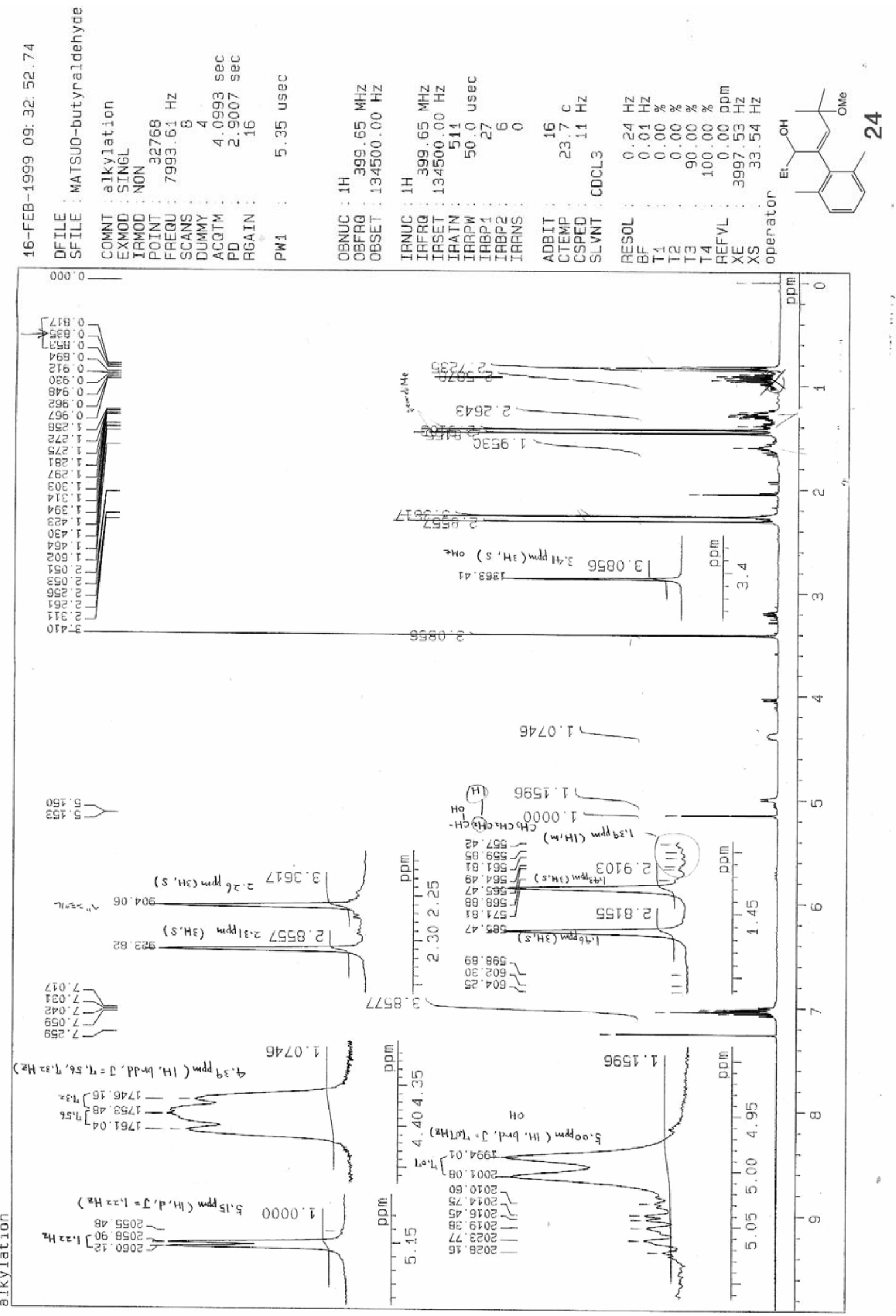




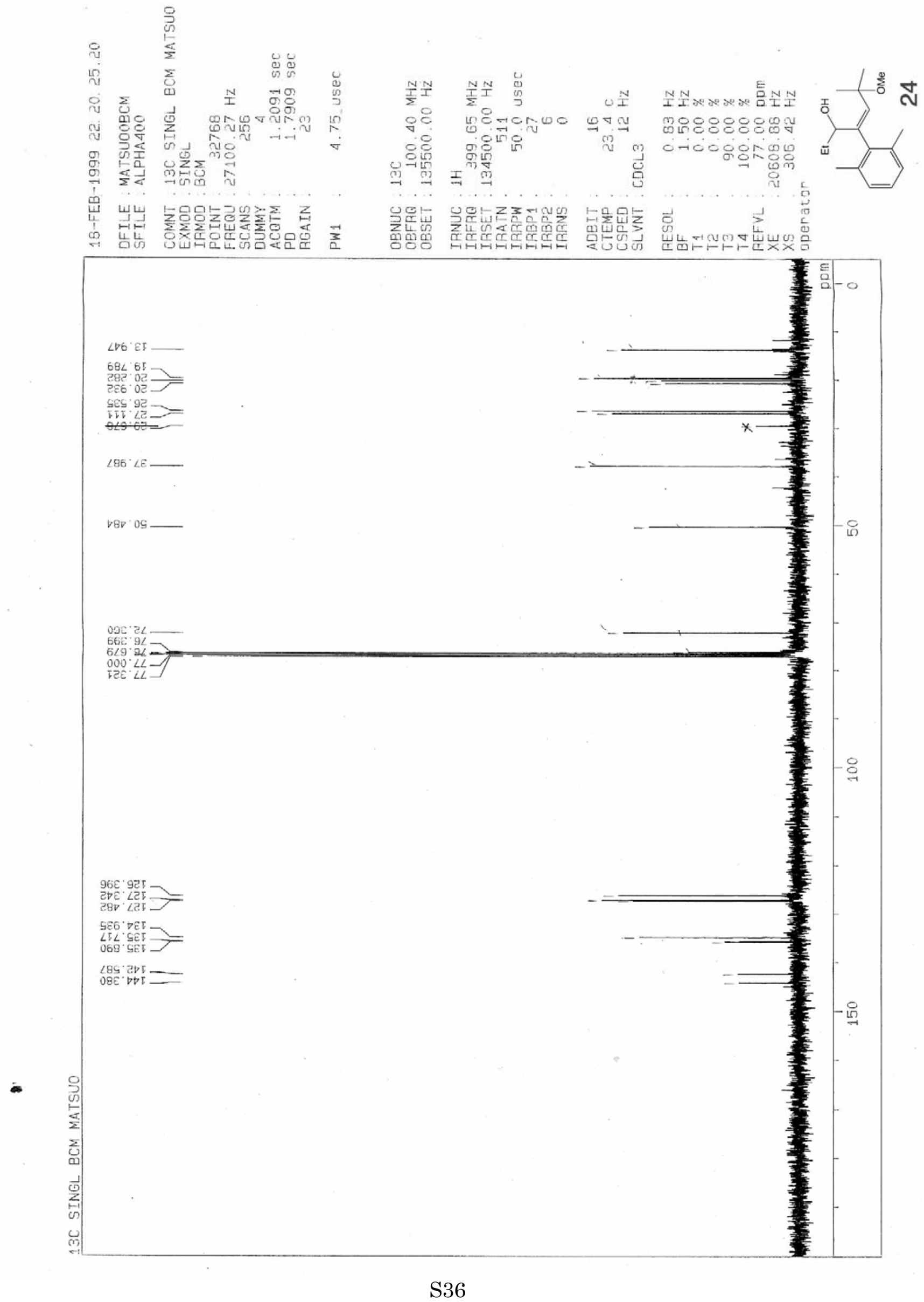




\section{Crystal data and structure refinement for $\mathbf{1 2}$}

Table 1 : Crystal data

$\mathrm{C}_{22} \mathrm{H}_{32} \mathrm{CrO}_{4} \mathrm{Si}$
$M_{r}=440.58$
Orthorhombic
Pnca
$a=18.168(4) \AA$
$b=27.585(7) \AA$
$c=9.004(3) \AA$
$V=4512(2) \AA^{3}$
$Z=8$
$D_{x}=1.297 \mathrm{Mg} \mathrm{m}^{-3}$

Table 2 : Data collection

Mac Science MXC18 diffractometer

$2 \theta / \omega$ scans

Absorption correction:

empirical

3927 measured reflections

3345 independent reflections

\section{Table 3 : Refinement}

Refinement on $F$

$R=0.062$

$w R=0.067$

$S=6.063$

2454 reflections

248 parameters

$\mathrm{H}$-atom parameters not refined

Count statistics
$\mathrm{Cu} K \alpha$ radiation

$\lambda=1.5418 \AA$

Cell parameters from 21 reflections

$\theta=28.3-30.0^{\circ}$

$\mu=48.727 \mathrm{~mm}^{-1}$

$T=150 \mathrm{~K}$

Prizm

$0.25 \times 0.20 \times 0.10 \mathrm{~mm}$

Yellow
2454 observed reflections

$$
\begin{aligned}
& \quad[I>3.00 \operatorname{sigma}(I)] \\
& \theta_{\max }=49.65^{\circ} \\
& h=0 \rightarrow 20 \\
& k=-30 \rightarrow 0 \\
& l=0 \rightarrow 10
\end{aligned}
$$

$(\Delta / \sigma)_{\max }=0.0501$

$\Delta \rho_{\max }=2.08 \mathrm{e} \AA^{-3}$

$\Delta \rho_{\min }=-0.90$ e $\AA^{-3}$

Extinction correction: Larson

Extinction coefficient: 6.414

Atomic scattering factors from

D. Waasmaier\&A. Kirfel, Acta

Cryst.1995, 151, 416-431

Data collection: MXC(MAC Science). Cell refinement: MXC(MAC Science). Data reduction: maXus. Program(s) used to solve structure: maXus. Program(s) used to refine structure: maXus. Molecular graphics: maXus. Software used to prepare material for publication: maXus. 
Table 4 ; FRACTIONAL ATOMIC COORDINATES \& U(iso)

\begin{tabular}{|c|c|c|c|c|}
\hline Atom & $x / a$ & $y / b$ & $z / c$ & $U($ iso $)$ \\
\hline $\operatorname{Cr}(21)$ & $0.56979(3)$ & $0.16921(2)$ & $0.15866(7)$ & $0.0210(3)$ \\
\hline Si (5) & $0.34390(5)$ & $0.11036(4)$ & $0.4491(1)$ & $0.0192(5)$ \\
\hline $0(24)$ & $0.6995(2)$ & $0.2217(1)$ & $0.0308(4)$ & $0.036(2)$ \\
\hline $0(23)$ & $0.5194(2)$ & $0.1435(1)$ & $-0.1483(3)$ & $0.041(2)$ \\
\hline $0(3)$ & $0.3180(2)$ & $0.0258(1)$ & $0.2587(4)$ & $0.044(2)$ \\
\hline $0(22)$ & $0.6663(2)$ & $0.0813(1)$ & $0.1644(5)$ & $0.049(2)$ \\
\hline$c(8)$ & $0.5746(2)$ & $0.1908(2)$ & $0.3954(4)$ & $0.022(2)$ \\
\hline$c(6)$ & $0.4676(2)$ & $0.1495(1)$ & $0.2880(4)$ & $0.018(2)$ \\
\hline$c(10)$ & $0.4989(2)$ & $0.2325(1)$ & $0.2139(5)$ & $0.023(2)$ \\
\hline$c(5)$ & $0.4135(2)$ & $0.1073(1)$ & $0.2890(4)$ & $0.015(2)$ \\
\hline$c(7)$ & $0.5290(2)$ & $0.1489(2)$ & $0.3855(4)$ & $0.018(2)$ \\
\hline$c(9)$ & $0.5599(2)$ & $0.231 /(1)$ & $0.3106(4)$ & $0.023(2)$ \\
\hline$c(11)$ & $0.4535(2)$ & $0.1908(1)$ & $0.2002(4)$ & $0.017(2)$ \\
\hline$C(4)$ & $0.4227(2)$ & $0.0731(1)$ & $0.1870(4)$ & $0.019(2)$ \\
\hline$C(22)$ & $0.6285(2)$ & $0.1144(2)$ & $0.1632(5)$ & $0.028(2)$ \\
\hline$C(23)$ & $0.5389(2)$ & $0.1530(2)$ & $-0.0310(5)$ & $0.026(2)$ \\
\hline$c(13)$ & $0.5468(2)$ & $0.1053(2)$ & $0.4785(5)$ & $0.026(2)$ \\
\hline$C(24)$ & $0.6498(2)$ & $0.2013(1)$ & $0.0799(4)$ & $0.023(2)$ \\
\hline$c(3)$ & $0.3770(2)$ & $0.0291(1)$ & $0.1531(5)$ & $0.023(2)$ \\
\hline$C(1)$ & $0.3463(3)$ & $0.0339(2)$ & $-0.0031(6)$ & $0.040(3)$ \\
\hline$C(12)$ & $0.3899(2)$ & $0.1924(2)$ & $0.0929(5)$ & $0.031(2)$ \\
\hline$c(14)$ & $0.2431(2)$ & $0.1111(2)$ & $0.4015(5)$ & $0.028(2)$ \\
\hline$c(15)$ & $0.2192(3)$ & $0.1448(3)$ & $0.2780(7)$ & $0.053(3)$ \\
\hline$C(16)$ & $0.3622(2)$ & $0.1698(2)$ & $0.5459(5)$ & $0.037(2)$ \\
\hline$C(19)$ & $0.3959(7)$ & $0.0149(5)$ & $0.536(1)$ & $0.095(5)$ \\
\hline$c(17)$ & $0.3143(3)$ & $0.1796(2)$ & $0.6803(6)$ & $0.050(3)$ \\
\hline$C(2)$ & $0.4221(3)$ & $-0.0171(2)$ & $0.1673(6)$ & $0.043(3)$ \\
\hline$C(18)$ & $0.3643(3)$ & $0.0624(2)$ & $0.5956(7)$ & $0.052(3)$ \\
\hline$C(20)$ & $0.3056(9)$ & $0.0231(6)$ & $0.614(2)$ & $0.036(3)$ \\
\hline$H(8)$ & 0.61901 & 0.18971 & 0.46390 & 0.05000 \\
\hline$H(4)$ & 0.46455 & 0.07658 & 0.13203 & 0.05000 \\
\hline$H(12 A)$ & 0.34807 & 0.19954 & 0.13397 & 0.05000 \\
\hline$H(10)$ & 0.48637 & 0.25934 & 0.14518 & 0.05000 \\
\hline$H(13 A)$ & 0.53521 & 0.07486 & 0.43384 & 0.05000 \\
\hline $\begin{array}{l}H(13 B) \\
H(12 B)\end{array}$ & $\begin{array}{r}0.59471 \\
037817\end{array}$ & 0.10486 & 0.49704 & 0.05000 \\
\hline$h(14 A)$ & 0.21905 & $\begin{array}{l}.10274 \\
0.11385\end{array}$ & $\begin{array}{l}0.03 / 81 \\
0.49611\end{array}$ & 0.05000 \\
\hline$H(17 A)$ & 0.26848 & 0.17905 & 0.66480 & 0.05000 \\
\hline$H(9)$ & 0.59558 & 0.26215 & 0.30980 & 0.05000 \\
\hline$H(17 B)$ & 0.32468 & 0.20235 & 0.74720 & 0.05000 \\
\hline$H(13 C)$ & 0.52401 & 0.10606 & 0.55784 & 0.05000 \\
\hline$H(1 A)$ & 0.32012 & 0.00939 & -0.02604 & 0.05000 \\
\hline$H(1 B)$ & 0.38742 & 0.03499 & -0.07104 & 0.05000 \\
\hline$H(15 A)$ & 0.24451 & 0.13406 & 0.20112 & 0.05000 \\
\hline$H(2 A)$ & 0.38397 & -0.04184 & 0.13746 & 0.05000 \\
\hline$H(148)$ & 0.22275 & 0.07955 & 0.38631 & 0.05000 \\
\hline$H(12 C)$ & 0.39607 & 0.21714 & 0.02177 & 0.05000 \\
\hline$H(2 B)$ & 0.46447 & -0.01774 & 0.10036 & 0.05000 \\
\hline$H(17 C)$ & 0.31288 & 0.14995 & 0.73750 & 0.05000 \\
\hline$H(16 A)$ & 0.35199 & 0.19981 & 0.46664 & 0.05000 \\
\hline$H(2 C)$ & 0.44317 & -0.02174 & 0.26016 & 0.05000 \\
\hline$H(16 B)$ & 0.42009 & 0.17141 & 0.58004 & 0.05000 \\
\hline$H(1 \mathrm{C})$ & 0.31152 & 0.05349 & -0.01134 & 0.05000 \\
\hline$H(15 B)$ & 0.23551 & 0.17346 & 0.29432 & 0.05000 \\
\hline$H(15 \mathrm{C})$ & 0.16821 & 0.14606 & 0.27022 & 0.05000 \\
\hline$H(3)$ & 0.28770 & 0.03846 & 0.20784 & 0.05000 \\
\hline
\end{tabular}


Table 5 ; ANISOTROPIC THERMAL PARAMETERS

\begin{tabular}{|c|c|c|c|c|c|c|}
\hline Atom & U11 & U22 & U33 & U12 & U13 & U23 \\
\hline 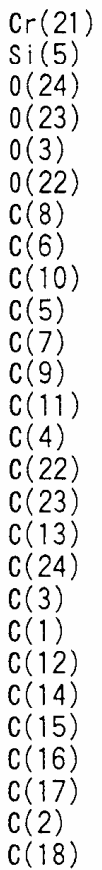 & $\begin{array}{l}0.0292(3) \\
0.0221(4) \\
0.030(1) \\
0.054(2) \\
0.046(2) \\
0.074(2) \\
0.028(2) \\
0.019(2) \\
0.030(2) \\
0.021(2) \\
0.024(2) \\
0.032(2) \\
0.022(2) \\
0.023(2) \\
0.047(2) \\
0.030(2) \\
0.027(2) \\
0.028(2) \\
0.030(2) \\
0.054(3) \\
0.034(2) \\
0.022(2) \\
0.025(2) \\
0.043(2) \\
0.053(3) \\
0.064(3) \\
0.047(3)\end{array}$ & $\begin{array}{l}0.0155(3) \\
0.0186(5) \\
0.036(2) \\
0.055(2) \\
0.045(2) \\
0.027(2) \\
0.022(2) \\
0.012(2) \\
0.010(2) \\
0.011(2) \\
0.018(2) \\
0.016(2) \\
0.013(2) \\
0.019(2) \\
0.019(2) \\
0.018(2) \\
0.029(2) \\
0.021(2) \\
0.020(2) \\
0.039(3) \\
0.027(2) \\
0.038(3) \\
0.077(4) \\
0.042(3) \\
0.066(4) \\
0.017(2) \\
0.056(3)\end{array}$ & $\begin{array}{l}0.0184(3) \\
0.0168(5) \\
0.041(2) \\
0.014(2) \\
0.041(2) \\
0.047(2) \\
0.015(2) \\
0.022(2) \\
0.029(2) \\
0.014(2) \\
0.012(2) \\
0.020(2) \\
0.017(2) \\
0.014(2) \\
0.016(2) \\
0.029(3) \\
0.021(2) \\
0.019(2) \\
0.021(2) \\
0.028(2) \\
0.030(2) \\
0.024(2) \\
0.058(3) \\
0.028(2) \\
0.030(3) \\
0.048(3) \\
0.053(3)\end{array}$ & $\begin{array}{l}-.0026(3) \\
-.0037(4) \\
-.010(1) \\
-.009(2) \\
-.020(2) \\
0.024(2) \\
-.010(2) \\
-.004(1) \\
-.001(2) \\
-.004(1) \\
-.005(2) \\
-.005(2) \\
-.003(1) \\
-.004(2) \\
0.004(2) \\
-.006(2) \\
-.004(2) \\
-.001(2) \\
-.008(2) \\
-.014(2) \\
-.001(2) \\
-.003(2) \\
0.008(2) \\
-.016(2) \\
-.011(3) \\
-.003(2) \\
-.004(3)\end{array}$ & $\begin{array}{l}0.0012(3) \\
0.0003(4) \\
0.008(1) \\
-.002(1) \\
0.018(2) \\
0.002(2) \\
0.002(2) \\
0.006(1) \\
0.008(2) \\
-.003(1) \\
0.003(1) \\
0.009(2) \\
0.005(1) \\
-.002(1) \\
0.004(2) \\
0.005(2) \\
0.000(2) \\
-.001(2) \\
0.003(2) \\
-.014(2) \\
-.001(2) \\
-.003(2) \\
0.001(2) \\
0.012(2) \\
0.013(2) \\
-.008(3) \\
-.001(2)\end{array}$ & $\begin{array}{l}0.0001(3) \\
0.0032(4) \\
0.008(2) \\
-.014(2) \\
-.014(2) \\
-.003(2) \\
-.007(2) \\
-.001(1) \\
0.000(2) \\
0.001(1) \\
-.001(1) \\
-.011(2) \\
-.001(1) \\
0.003(1) \\
-.004(2) \\
0.004(2) \\
0.007(2) \\
0.002(2) \\
-.002(2) \\
-.008(2) \\
0.008(2) \\
0.000(2) \\
0.029(3) \\
-.010(2) \\
-.027(3) \\
0.000(2) \\
0.039(3)\end{array}$ \\
\hline
\end{tabular}

Table 6 ; INTRAMOLECULAR BOND LENGTHS

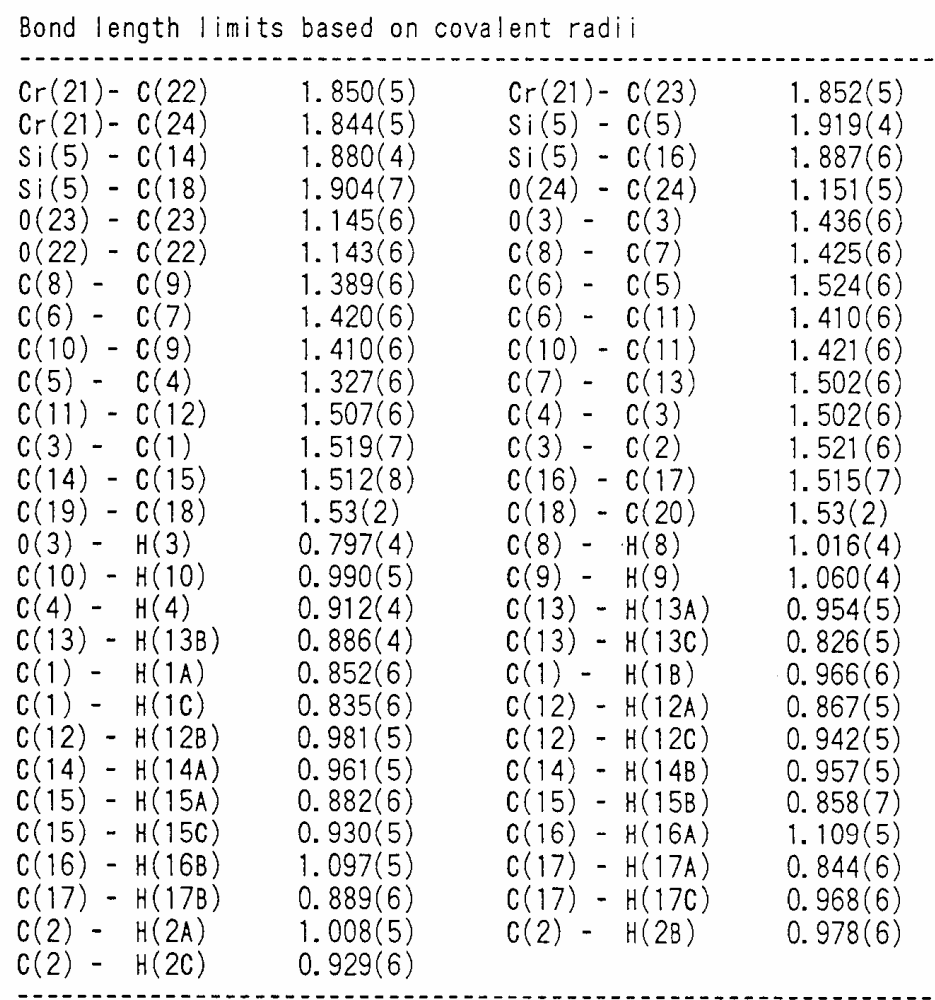


Table 7 ; INTRAMOLECULAR BOND ANGLES

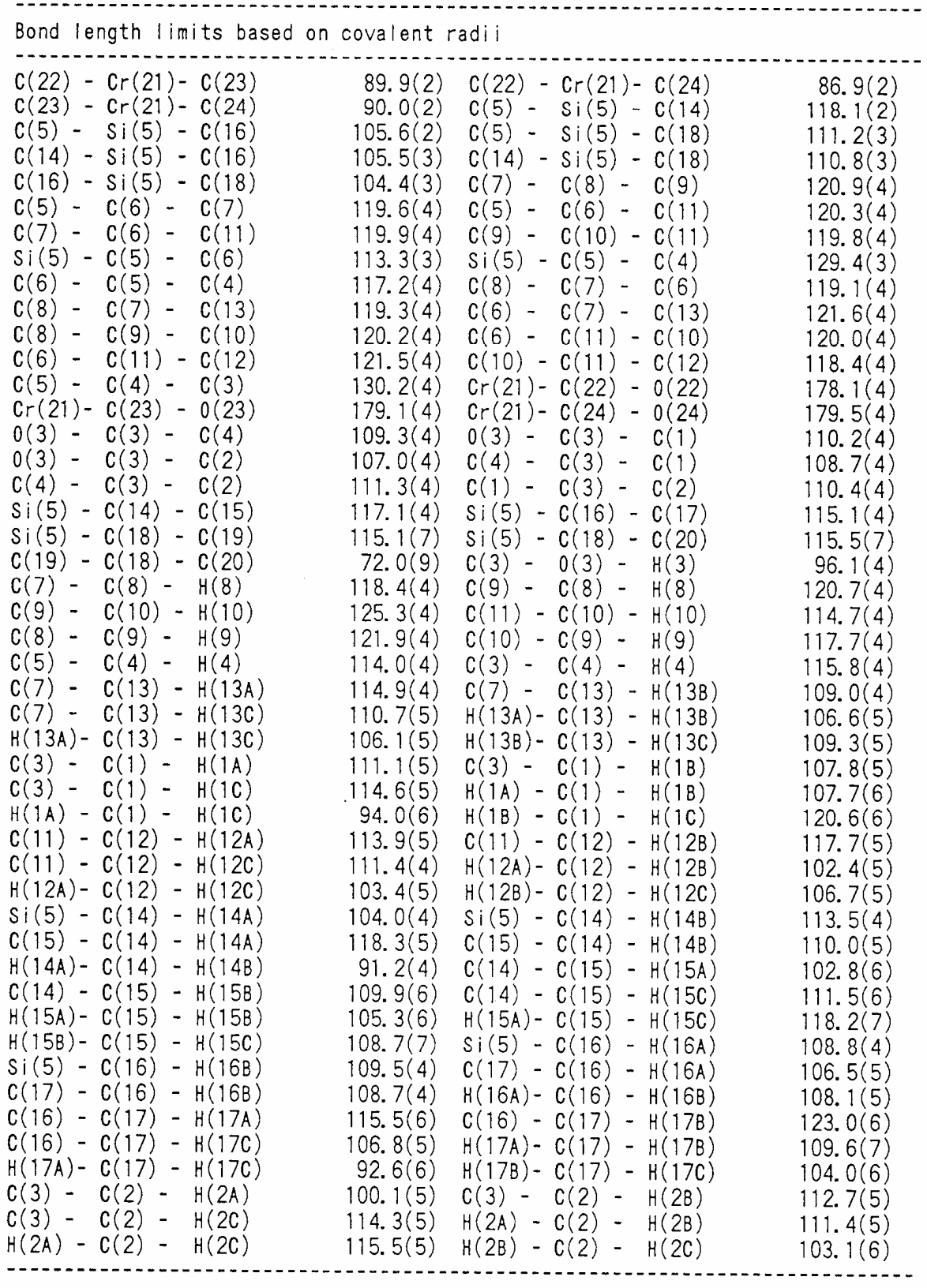


Table 8 ; INTRAMOLECULAR TORSION ANGLES (H omitted)

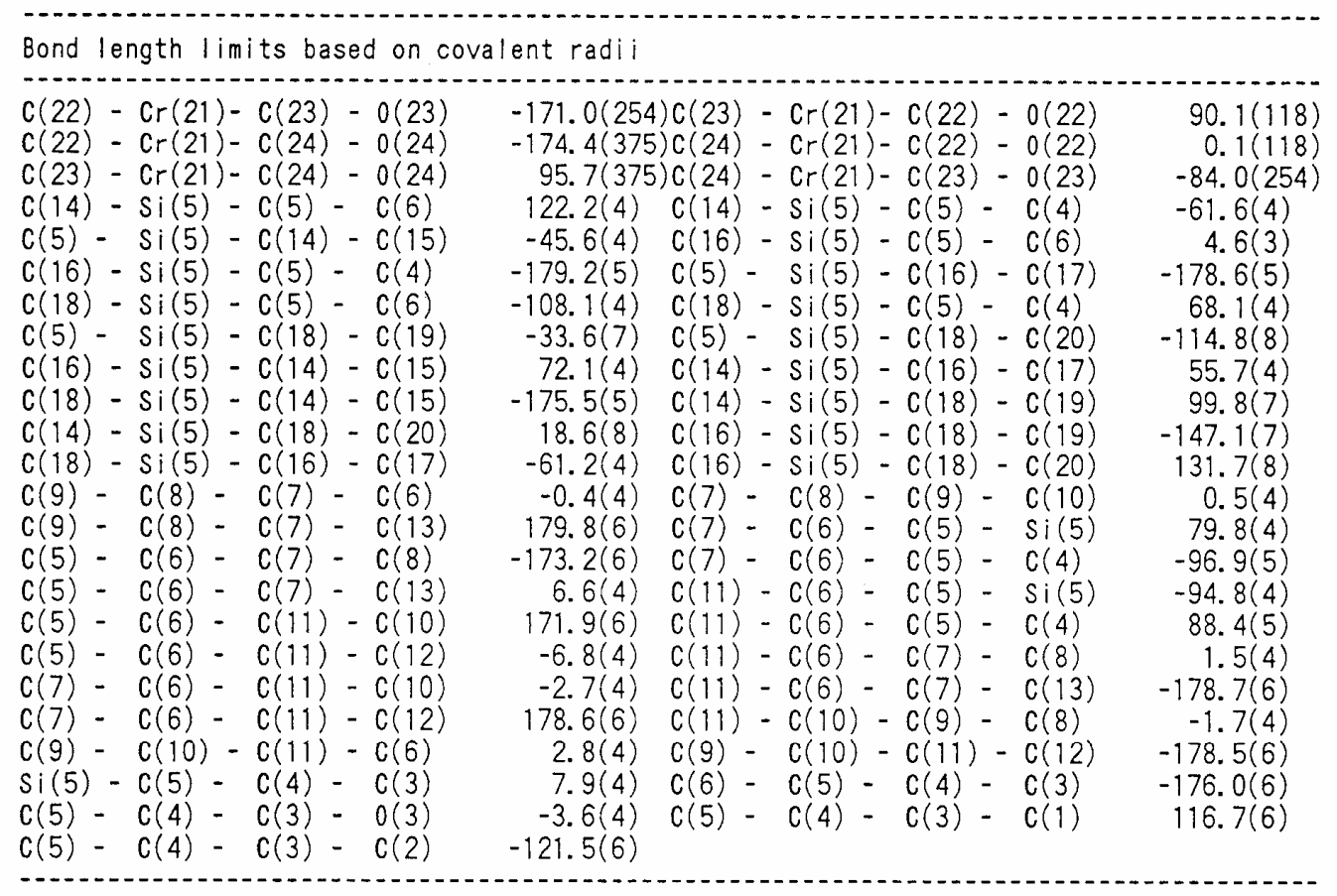


Table S1. Optimized Cartesian coordinates for compound $\mathbf{1 b}$.

\begin{tabular}{|c|c|c|c|}
\hline \multicolumn{4}{|c|}{$\begin{array}{l}\text { Method: RHF/6-31G* } \\
\text { Total Energy = -538.557427008 au }\end{array}$} \\
\hline \multirow[t]{2}{*}{ Atom } & \multicolumn{3}{|c|}{ Coordinates $(\AA)$} \\
\hline & $\mathrm{X}$ & $\mathrm{Y}$ & $\mathrm{Z}$ \\
\hline $\mathrm{C}$ & 0.000000 & 0.000000 & 0.000000 \\
\hline $\mathrm{C}$ & 0.000000 & 0.000000 & 1.391382 \\
\hline $\mathrm{C}$ & 1.189396 & 0.000000 & 2.098387 \\
\hline $\mathrm{C}$ & 2.403637 & -0.000029 & 1.428998 \\
\hline $\mathrm{C}$ & 2.417333 & 0.011686 & 0.044978 \\
\hline $\mathrm{C}$ & 1.224521 & 0.023906 & -0.659904 \\
\hline $\mathrm{C}$ & -1.247715 & 0.089543 & -0.808503 \\
\hline $\mathrm{C}$ & -2.353306 & -0.639788 & -0.831903 \\
\hline $\mathrm{C}$ & -2.772951 & -1.893811 & -0.092633 \\
\hline $\mathrm{O}$ & -1.686183 & -2.309773 & 0.691969 \\
\hline $\mathrm{C}$ & -3.991198 & -1.561553 & 0.784053 \\
\hline $\mathrm{C}$ & -3.142730 & -2.956372 & -1.139966 \\
\hline $\mathrm{C}$ & -1.743681 & -3.520875 & 1.380246 \\
\hline $\mathrm{H}$ & -2.603803 & -3.586083 & 2.039784 \\
\hline $\mathrm{H}$ & -1.752387 & -4.374165 & 0.709596 \\
\hline $\mathrm{H}$ & -0.846798 & -3.568725 & 1.982212 \\
\hline $\mathrm{H}$ & -3.712621 & -0.852893 & 1.555628 \\
\hline $\mathrm{H}$ & -4.782627 & -1.121489 & 0.186699 \\
\hline $\mathrm{H}$ & -4.397339 & -2.448246 & 1.258914 \\
\hline $\mathrm{H}$ & -3.551549 & -3.847880 & -0.676742 \\
\hline $\mathrm{H}$ & -3.892918 & -2.572903 & -1.822762 \\
\hline $\mathrm{H}$ & -2.266408 & -3.233756 & -1.714979 \\
\hline $\mathrm{H}$ & -3.110572 & -0.311756 & -1.526760 \\
\hline $\mathrm{H}$ & 1.168530 & 0.002403 & 3.174110 \\
\hline $\mathrm{H}$ & 3.352438 & 0.017882 & -0.486810 \\
\hline $\mathrm{H}$ & 3.326895 & -0.001561 & 1.980903 \\
\hline $\mathrm{H}$ & -0.934438 & -0.002008 & 1.918484 \\
\hline $\mathrm{H}$ & 1.244439 & 0.044244 & -1.736017 \\
\hline $\mathrm{H}$ & -1.230086 & 0.907655 & -1.512612 \\
\hline
\end{tabular}


Table S2. Optimized Cartesian coordinates for compound 2.

\begin{tabular}{lccc}
\hline \multicolumn{3}{c}{ Method: RHF/6-31G* } \\
Total Energy $=-577.593580473$ au \\
Atom & \multicolumn{3}{c}{ Coordinates $(\AA)$} \\
\multicolumn{4}{c}{$\mathrm{Y}$} \\
\hline $\mathrm{C}$ & $\mathrm{X}$ & $\mathrm{Z}$ \\
$\mathrm{C}$ & 0.000000 & 0.000000 & 0.000000 \\
$\mathrm{C}$ & 1.000000 & 0.000000 & 1.387238 \\
$\mathrm{C}$ & 2.390232 & 0.000000 & 2.106420 \\
$\mathrm{C}$ & 2.397435 & 0.008336 & 1.430855 \\
$\mathrm{C}$ & 1.218803 & 0.016799 & -0.687679 \\
$\mathrm{C}$ & -1.303221 & 0.078976 & -0.728804 \\
$\mathrm{C}$ & -2.148663 & -0.881987 & -1.059071 \\
$\mathrm{C}$ & -2.050048 & -2.382227 & -0.854620 \\
$\mathrm{O}$ & -0.683005 & -2.692168 & -0.729377 \\
$\mathrm{C}$ & -2.856735 & -2.765336 & 0.395193 \\
$\mathrm{C}$ & -2.622532 & -3.083038 & -2.095053 \\
$\mathrm{C}$ & -0.296469 & -3.935916 & -0.231407 \\
$\mathrm{H}$ & -0.534801 & -4.046496 & 0.821310 \\
$\mathrm{H}$ & -0.741909 & -4.761692 & -0.779189 \\
$\mathrm{H}$ & 0.777303 & -3.988901 & -0.345564 \\
$\mathrm{H}$ & -2.397364 & -2.348067 & 1.283499 \\
$\mathrm{H}$ & -3.865230 & -2.373242 & 0.319584 \\
$\mathrm{H}$ & -2.931976 & -3.841474 & 0.513283 \\
$\mathrm{H}$ & -2.575795 & -4.161658 & -1.993215 \\
$\mathrm{H}$ & -3.662295 & -2.813326 & -2.249648 \\
$\mathrm{H}$ & -2.057660 & -2.798302 & -2.975620 \\
$\mathrm{H}$ & -3.062925 & -0.575818 & -1.542823 \\
$\mathrm{H}$ & 1.162791 & -0.002784 & 3.181896 \\
$\mathrm{H}$ & 3.338637 & 0.024273 & -0.478379 \\
$\mathrm{H}$ & 3.319456 & 0.010759 & 1.972918 \\
$\mathrm{H}$ & -0.939994 & 0.003755 & 1.910520 \\
$\mathrm{C}$ & 1.256185 & 0.007048 & -2.197829 \\
$\mathrm{H}$ & -1.597584 & 1.082528 & -1.000008 \\
$\mathrm{H}$ & 0.794046 & -0.894134 & -2.585133 \\
$\mathrm{H}$ & 0.718627 & 0.852937 & -2.616743 \\
$\mathrm{H}$ & 2.276879 & 0.050716 & -2.560408 \\
\hline & & & \\
\hline
\end{tabular}


Table S3. Optimized Cartesian coordinates for compound 3.

\begin{tabular}{|c|c|c|c|}
\hline \multirow{2}{*}{\multicolumn{4}{|c|}{$\begin{array}{l}\text { Method: RHF/6-31G* } \\
\text { Total Energy = -577.594446450 au }\end{array}$}} \\
\hline & & & \\
\hline Atom & $\mathrm{X}$ & $\mathrm{Y}$ & $\mathrm{Z}$ \\
\hline C & 0.000000 & 0.000000 & 0.000000 \\
\hline C & 0.000000 & 0.000000 & 1.392167 \\
\hline $\mathrm{C}$ & 1.185306 & 0.000000 & 2.101614 \\
\hline $\mathrm{C}$ & 2.417383 & -0.002124 & 1.453711 \\
\hline $\mathrm{C}$ & 2.418205 & 0.012562 & 0.067368 \\
\hline $\mathrm{C}$ & 1.229359 & 0.025615 & -0.645730 \\
\hline $\mathrm{C}$ & -1.239957 & 0.089320 & -0.818421 \\
\hline $\mathrm{C}$ & -2.366771 & -0.607956 & -0.824270 \\
\hline $\mathrm{C}$ & -2.833429 & -1.820523 & -0.044948 \\
\hline $\mathrm{O}$ & -1.765206 & -2.250299 & 0.758035 \\
\hline $\mathrm{C}$ & -4.042016 & -1.417153 & 0.815037 \\
\hline $\mathrm{C}$ & -3.237645 & -2.903577 & -1.058117 \\
\hline $\mathrm{C}$ & -1.868407 & -3.437642 & 1.481206 \\
\hline $\mathrm{H}$ & -2.735799 & -3.455154 & 2.134229 \\
\hline $\mathrm{H}$ & -1.899724 & -4.309731 & 0.835865 \\
\hline $\mathrm{H}$ & -0.978724 & -3.497256 & 2.092853 \\
\hline $\mathrm{H}$ & -3.741636 & -0.693142 & 1.563790 \\
\hline $\mathrm{H}$ & -4.815570 & -0.969952 & 0.199825 \\
\hline $\mathrm{H}$ & -4.480489 & -2.272862 & 1.317307 \\
\hline $\mathrm{H}$ & -3.677145 & -3.765230 & -0.567226 \\
\hline $\mathrm{H}$ & -3.973341 & -2.517285 & -1.754902 \\
\hline $\mathrm{H}$ & -2.370433 & -3.229064 & -1.621636 \\
\hline $\mathrm{H}$ & -3.107750 & -0.282573 & -1.537731 \\
\hline $\mathrm{H}$ & 1.152687 & 0.005889 & 3.178201 \\
\hline $\mathrm{H}$ & 3.352949 & 0.022044 & -0.466566 \\
\hline $\mathrm{C}$ & 3.706180 & -0.030365 & 2.241994 \\
\hline $\mathrm{H}$ & -0.933676 & 0.002103 & 1.920166 \\
\hline $\mathrm{H}$ & 1.261980 & 0.050489 & -1.721619 \\
\hline $\mathrm{H}$ & -1.195872 & 0.877931 & -1.554337 \\
\hline $\mathrm{H}$ & 3.909928 & -1.027770 & 2.622974 \\
\hline $\mathrm{H}$ & 4.550113 & 0.265191 & 1.628920 \\
\hline $\mathrm{H}$ & 3.661931 & 0.639980 & 3.094291 \\
\hline
\end{tabular}


Table S4. Optimized Cartesian coordinates for compound $\mathbf{4 b .}$

\begin{tabular}{lccc}
\hline \multicolumn{3}{c}{ Method: RHF/6-31G* } \\
Total Energy $=-616.633292579$ au \\
Atom & \multicolumn{3}{c}{ Coordinates $(\AA)$} \\
\multicolumn{3}{c}{$\mathrm{Y}$} \\
\hline $\mathrm{C}$ & $\mathrm{X}$ & $\mathrm{Z}$ \\
$\mathrm{C}$ & 0.000000 & 0.000000 & 0.000000 \\
$\mathrm{C}$ & 0.000000 & 0.000000 & 1.399472 \\
$\mathrm{C}$ & 1.218166 & 0.000000 & 2.072669 \\
$\mathrm{C}$ & 2.414677 & -0.004693 & 1.384978 \\
$\mathrm{C}$ & 2.410151 & -0.019022 & 0.001504 \\
$\mathrm{C}$ & 1.214990 & -0.022533 & -0.700679 \\
$\mathrm{C}$ & -1.272437 & -0.008233 & -0.782466 \\
$\mathrm{C}$ & -2.176085 & 0.953366 & -0.755147 \\
$\mathrm{O}$ & -3.474513 & 1.031908 & -1.533299 \\
$\mathrm{C}$ & -4.422152 & 1.353533 & -0.527019 \\
$\mathrm{C}$ & -3.352923 & 2.160955 & -2.567198 \\
$\mathrm{C}$ & -3.848575 & -0.283785 & -2.217274 \\
$\mathrm{H}$ & -5.715487 & 1.732622 & -0.887219 \\
$\mathrm{H}$ & -5.735807 & 2.688778 & -1.400944 \\
$\mathrm{H}$ & -6.211011 & 0.992948 & -1.508461 \\
$\mathrm{H}$ & -6.273188 & 1.829266 & 0.034495 \\
$\mathrm{H}$ & -3.164500 & 3.108975 & -2.074425 \\
$\mathrm{H}$ & -2.527868 & 1.957504 & -3.240313 \\
$\mathrm{H}$ & -4.252408 & 2.259795 & -3.165707 \\
$\mathrm{H}$ & -4.787481 & -0.188932 & -2.750331 \\
$\mathrm{H}$ & -3.097222 & -0.571964 & -2.943551 \\
$\mathrm{H}$ & -3.949747 & -1.076192 & -1.485324 \\
$\mathrm{H}$ & -2.013391 & 1.813244 & -0.126520 \\
$\mathrm{H}$ & 1.223405 & -0.003010 & 3.148635 \\
$\mathrm{H}$ & 3.341877 & -0.027222 & -0.536573 \\
$\mathrm{C}$ & 3.346637 & -0.004557 & 1.922321 \\
$\mathrm{C}$ & -1.278279 & -0.016446 & 2.212375 \\
$\mathrm{H}$ & 1.236463 & -0.037748 & -2.213406 \\
$\mathrm{H}$ & -1.420123 & -0.863355 & -1.421446 \\
$\mathrm{H}$ & 0.782763 & -0.941624 & -2.611185 \\
$\mathrm{H}$ & 0.690211 & 0.803818 & -2.626463 \\
$\mathrm{H}$ & 2.253702 & 0.007714 & -2.583825 \\
$\mathrm{H}$ & -2.012200 & -0.694061 & 1.794789 \\
& -1.070213 & -0.326619 & 3.230002 \\
& -1.740805 & 0.964103 & 2.257071 \\
\hline & & &
\end{tabular}


Table S5. Optimized Cartesian coordinates for compound 5.

\begin{tabular}{|c|c|c|c|}
\hline \multicolumn{4}{|c|}{$\begin{array}{l}\text { Method: RHF/6-31G* } \\
\text { Total Energy = -577.601243284 au }\end{array}$} \\
\hline \multirow[t]{2}{*}{ Atom } & \multicolumn{3}{|c|}{ Coordinates $(\AA)$} \\
\hline & $\mathrm{X}$ & $\mathrm{Y}$ & $\mathrm{Z}$ \\
\hline $\mathrm{C}$ & 0.000000 & 0.000000 & 0.000000 \\
\hline $\mathrm{C}$ & 0.000000 & 0.000000 & 1.391422 \\
\hline $\mathrm{C}$ & 1.182682 & 0.000000 & 2.111183 \\
\hline $\mathrm{C}$ & 2.390640 & -0.010928 & 1.439177 \\
\hline $\mathrm{C}$ & 2.402527 & -0.023402 & 0.053613 \\
\hline $\mathrm{C}$ & 1.225400 & -0.021569 & -0.681778 \\
\hline $\mathrm{C}$ & -1.282387 & 0.007000 & -0.750206 \\
\hline $\mathrm{C}$ & -2.345784 & 0.713266 & -0.407008 \\
\hline $\mathrm{C}$ & -3.685954 & 0.772691 & -1.112246 \\
\hline $\mathrm{O}$ & -4.607524 & 0.601243 & -0.046892 \\
\hline $\mathrm{C}$ & -3.832417 & 2.157471 & -1.760233 \\
\hline $\mathrm{C}$ & -3.867834 & -0.330505 & -2.155778 \\
\hline $\mathrm{C}$ & -5.967119 & 0.827458 & -0.262350 \\
\hline $\mathrm{H}$ & -6.184439 & 1.873714 & -0.453936 \\
\hline $\mathrm{H}$ & -6.366517 & 0.233733 & -1.078782 \\
\hline $\mathrm{H}$ & -6.473150 & 0.535449 & 0.647914 \\
\hline $\mathrm{H}$ & -3.781917 & 2.936810 & -1.007154 \\
\hline $\mathrm{H}$ & -3.029611 & 2.318804 & -2.470498 \\
\hline $\mathrm{H}$ & -4.772351 & 2.257182 & -2.292953 \\
\hline $\mathrm{H}$ & -4.843845 & -0.264006 & -2.622287 \\
\hline $\mathrm{H}$ & -3.130701 & -0.244407 & -2.945967 \\
\hline $\mathrm{H}$ & -3.774694 & -1.306513 & -1.694772 \\
\hline $\mathrm{H}$ & -2.301358 & 1.352524 & 0.459053 \\
\hline $\mathrm{H}$ & 1.156736 & -0.001693 & 3.186350 \\
\hline $\mathrm{H}$ & 3.345176 & -0.031329 & -0.465553 \\
\hline $\mathrm{H}$ & 3.317731 & -0.015053 & 1.984455 \\
\hline $\mathrm{H}$ & -0.939252 & -0.019384 & 1.913524 \\
\hline $\mathrm{C}$ & 1.284273 & -0.025801 & -2.193553 \\
\hline $\mathrm{H}$ & -1.315257 & -0.612878 & -1.628657 \\
\hline $\mathrm{H}$ & 0.868950 & -0.940291 & -2.608743 \\
\hline $\mathrm{H}$ & 0.726735 & 0.803916 & -2.616185 \\
\hline $\mathrm{H}$ & 2.308540 & 0.052090 & -2.537971 \\
\hline
\end{tabular}


Table S6. Optimized Cartesian coordinates for compound 6.

\begin{tabular}{|c|c|c|c|}
\hline \multicolumn{4}{|c|}{$\begin{array}{l}\text { Method: RHF/6-31G* } \\
\text { Total Energy = -577.603486516 au }\end{array}$} \\
\hline \multirow{2}{*}{ Atom } & \multicolumn{3}{|c|}{ Coordinates $(\AA)$} \\
\hline & $\mathrm{X}$ & $\mathrm{Y}$ & $\mathrm{Z}$ \\
\hline C & 0.000000 & 0.000000 & 0.000000 \\
\hline $\mathrm{C}$ & 0.000000 & 0.000000 & 1.396013 \\
\hline $\mathrm{C}$ & 1.182933 & 0.000000 & 2.105787 \\
\hline $\mathrm{C}$ & 2.417314 & -0.008468 & 1.458772 \\
\hline $\mathrm{C}$ & 2.418713 & -0.023876 & 0.073455 \\
\hline $\mathrm{C}$ & 1.230808 & -0.024485 & -0.642639 \\
\hline $\mathrm{C}$ & -1.241582 & 0.011787 & -0.807713 \\
\hline $\mathrm{C}$ & -2.428187 & 0.430512 & -0.402204 \\
\hline $\mathrm{C}$ & -3.713715 & 0.479075 & -1.203349 \\
\hline $\mathrm{O}$ & -4.659843 & -0.091090 & -0.312255 \\
\hline $\mathrm{C}$ & -4.044494 & 1.948948 & -1.502612 \\
\hline $\mathrm{C}$ & -3.648423 & -0.330801 & -2.499123 \\
\hline $\mathrm{C}$ & -6.021756 & -0.015319 & -0.604112 \\
\hline $\mathrm{H}$ & -6.396498 & 1.002536 & -0.557116 \\
\hline $\mathrm{H}$ & -6.265884 & -0.431476 & -1.576628 \\
\hline $\mathrm{H}$ & -6.528766 & -0.600281 & 0.151361 \\
\hline $\mathrm{H}$ & -4.168404 & 2.506020 & -0.579878 \\
\hline $\mathrm{H}$ & -3.236764 & 2.401089 & -2.066502 \\
\hline $\mathrm{H}$ & -4.953790 & 2.048014 & -2.086344 \\
\hline $\mathrm{H}$ & -4.592207 & -0.286684 & -3.030086 \\
\hline $\mathrm{H}$ & -2.889720 & 0.062107 & -3.166213 \\
\hline $\mathrm{H}$ & -3.423602 & -1.368889 & -2.285545 \\
\hline $\mathrm{H}$ & -2.551994 & 0.809893 & 0.597881 \\
\hline $\mathrm{H}$ & 1.149300 & -0.003526 & 3.182209 \\
\hline $\mathrm{H}$ & 3.353756 & -0.037344 & -0.459375 \\
\hline $\mathrm{C}$ & 3.702540 & -0.009487 & 2.252902 \\
\hline $\mathrm{H}$ & -0.931435 & -0.018866 & 1.931588 \\
\hline $\mathrm{H}$ & 1.266618 & -0.037450 & -1.718519 \\
\hline $\mathrm{H}$ & -1.119540 & -0.345610 & -1.815776 \\
\hline $\mathrm{H}$ & 4.567993 & -0.042505 & 1.601290 \\
\hline $\mathrm{H}$ & 3.784222 & 0.881956 & 2.868065 \\
\hline $\mathrm{H}$ & 3.753503 & -0.867612 & 2.916557 \\
\hline
\end{tabular}

